\title{
Dynamical Modulation of Wintertime Synoptic-Scale Cyclone Activity over the Japan Sea due to Changbai Mountain in the Korean Peninsula
}

\author{
Hiroyuki Shimizu, ${ }^{1}$ Ryuichi Kawamura, ${ }^{1}$ Tetsuya Kawano, ${ }^{1}$ and Satoshi Iizuka ${ }^{2}$ \\ ${ }^{1}$ Department of Earth and Planetary Sciences, Faculty of Science, Kyushu University, Fukuoka, Japan \\ ${ }^{2}$ National Research Institute for Earth Science and Disaster Resilience, Tsukuba, Japan \\ Correspondence should be addressed to Ryuichi Kawamura; kawamura.ryuichi.130@m.kyushu-u.ac.jp
}

Received 22 January 2017; Accepted 13 March 2017; Published 27 April 2017

Academic Editor: Mario M. Miglietta

Copyright (C) 2017 Hiroyuki Shimizu et al. This is an open access article distributed under the Creative Commons Attribution License, which permits unrestricted use, distribution, and reproduction in any medium, provided the original work is properly cited.

The dynamical impact of the Changbai Mountain Range in the Korean Peninsula on the extratropical cyclone activity over the Japan Sea in early winter is examined using the Weather Research Forecasting model. We have conducted two independent long-term integrations over 15 winter months (December only) from 2000 to 2014 with and without modified topography. The results show that the Changbai Mountain Range plays a vital role in increasing cyclone track frequency, low-level poleward eddy heat flux, and the local deepening rate over the Japan Sea through enhancement of the lower-tropospheric baroclinic zone (LTBZ). This mountain range gives rise to activation of the synoptic-scale cyclone activity over that region. From our case study on three typical cyclones, it is found that mesoscale structures in the vicinity of a cyclone's center are dynamically modulated when it passes through the LTBZ and that cyclogenesis is triggered around that zone. A vorticity budget analysis shows that the stretching term relevant to enhanced low-level convergence plays a dominant role in intensifying cyclonic vorticities. We confirmed that the composite features of the three typical cases are consistent with the statistical ones of the dynamical modulation of the Changbai Mountain on synoptic-scale cyclone activity.

\section{Introduction}

Rapidly developing cyclones (Sanders and Gyakum [1]) often cause severe weather disasters, such as heavy snowfall, strong winds, and high waves, around northern Japan in winter. It is known that such cyclones tend to concentrate in the Japan Sea and the Kuroshio/Kuroshio Extension [2-4] in climate terms. Iizuka et al. [5] indicated that the concentrations of the explosive cyclones in these two regions are apparently shown when the East Asian winter monsoon is strengthened. They also postulated that when the monsoon is strong, a zonally elongated lower-tropospheric baroclinic zone (hereafter LTBZ) is pronounced over the Japan Sea. Since the LTBZ is located around the area where the Japan Sea polar air mass convergence zone (JPCZ) (Asai [6]) is dominant, a possible relationship between the two is suggested.
Nagata et al. [7] and Nagata [8,9] have examined the formation mechanism of the JPCZ using a primitive model. According to their research, three major factors are necessary for JPCZ formation: the existence of the mountains north of the Korean Peninsula (the Changbai Range and the Hamgyong Range), thermal contrast between the Japan Sea and the Korean Peninsula, and a subpolar front in the central Japan Sea. The JPCZ has been known to generate mesoscale cyclones, and such cyclones are frequently observed especially over the western Japan Sea (e.g., Asai [6]). Their cyclogenesis and developing mechanisms have been well investigated by Nagata [10], Tsuboki and Asai [11], and others. These previous studies suggest that the Changbai Mountain Range exerts an indirect influence on the cyclogenesis and development of mesoscale cyclones through formation of the JPCZ. 
If the LTBZ is interpreted as a climatological feature of the JPCZ, we anticipate that the existence of the Changbai Mountain Range is also necessary for the formation of the LTBZ. If so, this mountain range might influence not only a mesoscale cyclone but also synoptic-scale cyclone activity over the Japan Sea through enhancement of the LTBZ. Few studies have yet addressed the dynamical effect of the Changbai Mountain on the synoptic-scale cyclone activity in the vicinity of the Japan Sea in climate terms. Although it is not necessarily obvious why the dominant region of the synoptic-scale cyclone activity is split into the Japan Sea and the Kuroshio/Kuroshio Extension (e.g., Adachi and Kimura [12]), the intensification of the cyclone activity over the Japan Sea due to the Changbai Mountain may contribute to such a split.

The main objective of our study is to investigate the dynamical impact of high mountains in the vicinity of the Korean Peninsula on the synoptic-scale cyclones that migrated and developed over the Japan Sea, performing numerical experiments with the modified topography of the Korean Peninsula. In addition, we examine the influence of the sea surface temperature (SST) steepness on cyclone activity by comparing the simulations utilizing observed SST and spatially smoothed SST data to understand the relative importance of the subpolar front in the Japan Sea in cyclone activity compared to the orographic effect. The rest of the paper is organized as follows. We first give a brief description of the model used and the experimental design in Section 2. Section 3 describes the climatological differences in precipitation, lower-tropospheric baroclinicity, and synopticscale cyclone activity between the experiments with and without modified topography. Section 4 is an examination of how individual synoptic-scale cyclones are dynamically modulated by the Changbai Mountain, selecting three typical cases. The discussion and summary are presented in Sections 5 and 6 , respectively.

\section{Model Configurations and Experimental Design}

The model studies are carried out using the WRF-ARW model, version 3.5.1, which was developed by the National Center for Atmospheric Research (NCAR) (Skamarock et al. [13]). The model was run in the vicinity of Japan $\left(115.629^{\circ} \mathrm{E}-154.372^{\circ} \mathrm{E}, 22.962^{\circ} \mathrm{N}-48.858^{\circ} \mathrm{N}\right)$, divided into $346 \times 291$ grids with a spatial resolution of $10 \mathrm{~km}$. The model uses 35 vertical levels, with the top level at $50 \mathrm{hPa}$. The physical parameterization schemes used in this study include the Rapid Radiative Transfer Model (RRTM) long wave radiation (Mlawer et al. [14]) and Dudhia shortwave radiation (Dudhia [15]) schemes, the Noah scheme for surface processes (Chen et al. [16]), the Kain-Fritsch scheme (Kain [17]) for cumulus convection, the WRF single moment 6-class scheme (WSM6) (Hong and Lim [18]) for cloud microphysics, and the Yonsei University scheme for the planetary boundary layer. All experiments used the National Centers for Environmental Predictions-Final (NCEP FNL) operational model global tropospheric analyses. The 6hourly NCEP FNL data available at a $1^{\circ} \times 1^{\circ}$ resolution were

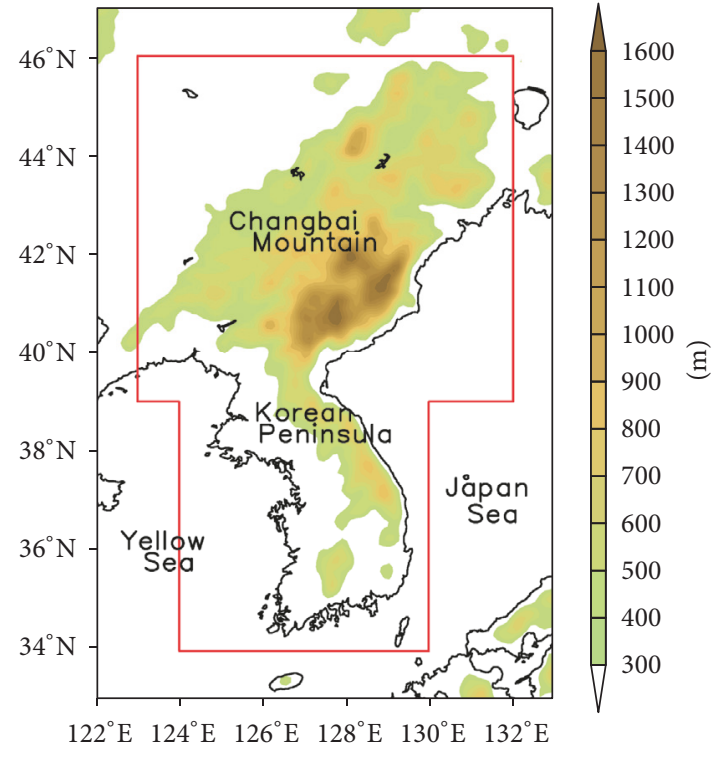

Figure 1: Topography in the vicinity of the Korean Peninsula. Shading denotes the surface height $(\mathrm{m})$ from sea level. The illustrated red rectangle designates the domain where mountain elevation is modified as a height of $0 \mathrm{~m}$.

used for initial and lateral boundary conditions. We also used the daily optimal interpolation sea surface temperature (OISST) data based only on the Pathfinder Advanced Very High Resolution Radiometer (AVHRR) (Reynolds et al. [19]) with a spatial grid resolution of $0.25^{\circ}$. Fifteen winter months (December only) for the period 2000-2014 were simulated because synoptic-scale cyclone activity over the Japan Sea is most prominent in December (e.g., Yoshiike and Kawamura [4], Hayasaki and Kawamura [20]). The initial time of the simulations is 00:00 UTC on November 23 every year, and each integration period is 47 days so that we apply low-pass filters to 3-hourly model output data, as mentioned later. We also conducted additional simulations with respect to individual cyclones that are generated and/or grow over the Japan Sea.

Figure 1 shows the topography around the Korean Peninsula. In the modified topography experiment (hereafter called the MOD run), we changed the mountain elevation to $0 \mathrm{~m}$ within the domain (red rectangle in the figure) to evaluate the dynamical influence of the Changbai Mountain Range and its surrounding areas on cyclone activity. The experiment without modified topography is the control (CTL) run. The cyclone tracking method used in this study is basically the same as that in Iizuka et al. [5]. Prior to the tracking procedure, the sea level pressure (SLP) fields were replaced by an average of the values in a $10 \times 10$ square of cells $(100 \mathrm{~km}$ $\times 100 \mathrm{~km}$ ) centered on the cell in question. The smoothing is done to avoid miss tracking. The initial appearance of an extratropical cyclone is defined when an hourly SLP at any grid point is at least $0.5 \mathrm{hPa}$ lower than the value at surrounding grid points. Synoptic-scale cyclones are defined as those that were tracked for more than 24 hours after the initial appearance. 


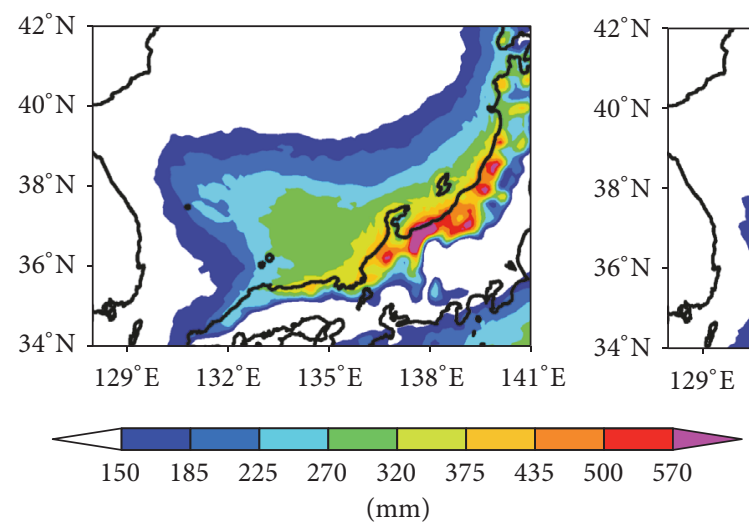

(a) CTL run
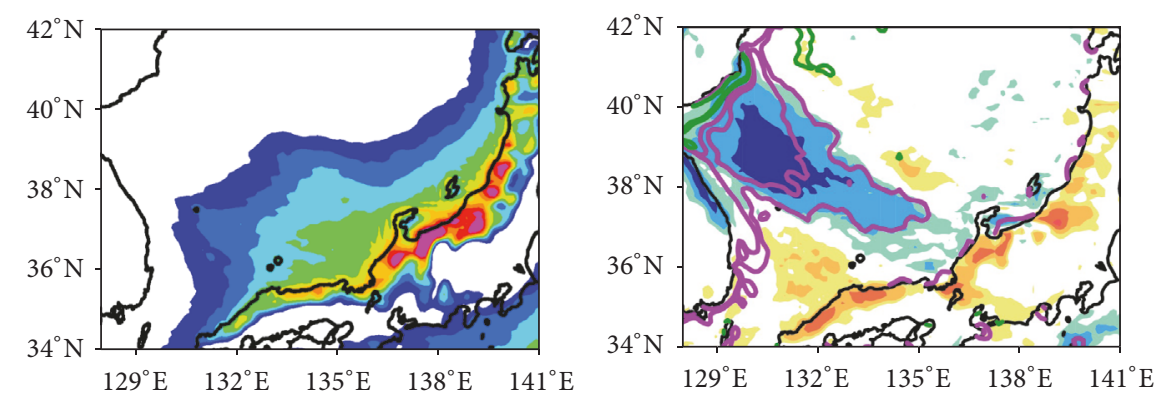

(b) MOD run

(c) Difference

Figure 2: (a) Climatological mean December precipitation during 2000-2014 for the CTL run. (b) As in Figure 2(a) but for the MOD run. (c) Differences in precipitation (shaded) and $925 \mathrm{hPa}$ horizontal wind divergence (contours) between the MOD and CTL runs (former minus latter). Purple and green contour lines denote positive and negative values, respectively. The contoured interval is $5 \times 10^{-6} \mathrm{~s}^{-1}$. Values of less than $5 \times 10^{-6} \mathrm{~s}^{-1}$ are suppressed.

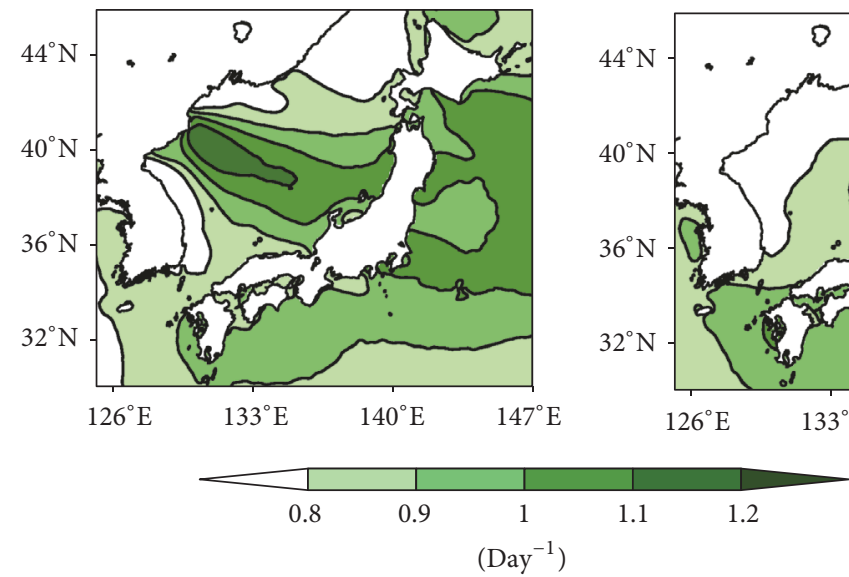

(a) CTL run

(b) MOD run

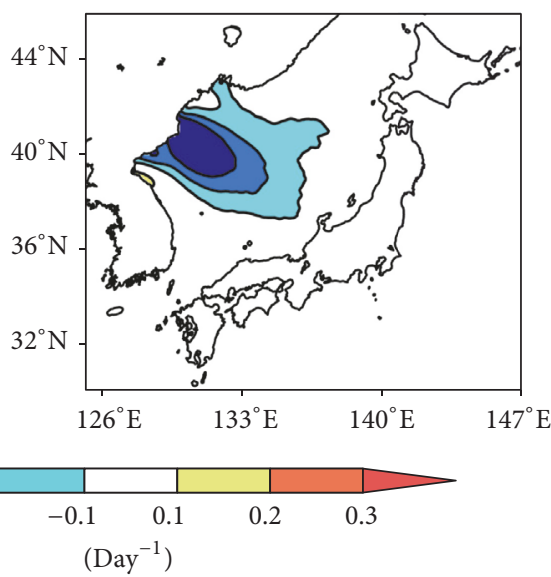

(c) Difference

FIgure 3: (a) Climatological mean December distribution of the maximum Eady growth rate for the CTL run. The shading interval is 0.1 day $^{-1}$. (b) As in Figure 3(a) but for the MOD run. (c) Difference in the maximum Eady growth rate between the MOD and CTL runs (former minus latter).

\section{Climatological Features}

3.1. Precipitation and Lower-Tropospheric Baroclinicity. Figure 2 reveals the climatological mean monthly precipitation in December for the CTL and the MOD runs based on the 15-year period from 2000 to 2014. The difference in the precipitation between the two runs is also shown, along with that in the divergence of a $925 \mathrm{hPa}$ horizontal wind. It is apparent that marked precipitation areas extend over the central Japan Sea in the CTL run, corresponding to the frequent occurrence of the JPCZ, but such a feature is less clear in the MOD run. The decrease in precipitation is evident around the region downstream of the Changbai Mountain, accompanied by an anomalous horizontal wind divergence at the $925 \mathrm{hPa}$ level. This implies the weakening and/or decreased occurrence of the JPCZ, which is quite consistent with the results of Nagata et al. [7] and Nagata [9].
In contrast, the amount of precipitation increases on the Japan Sea side of central and western Japan. Since part of a large amount of moisture due to surface evaporation from the ocean is consumed by condensation within the JPCZ, the weakened and less organized JPCZ, in turn, facilitates increased moisture transport toward the coastal regions of central and western Japan, eventually contributing to enhanced rainfall in those regions. We thus confirm that the Changbai Mountain Range significantly affects the geographical distribution of precipitation over the Japan Sea and its coastal areas of central and western Japan through formation of the JPCZ.

Another important view is the significant role of the Changbai Mountain in the lower-tropospheric baroclinicity over the Japan Sea. Figure 3 displays the climatological distributions of the maximum Eady growth rate (hereafter EGR) (Lindzen and Farrell [21]) in December for the CTL and 

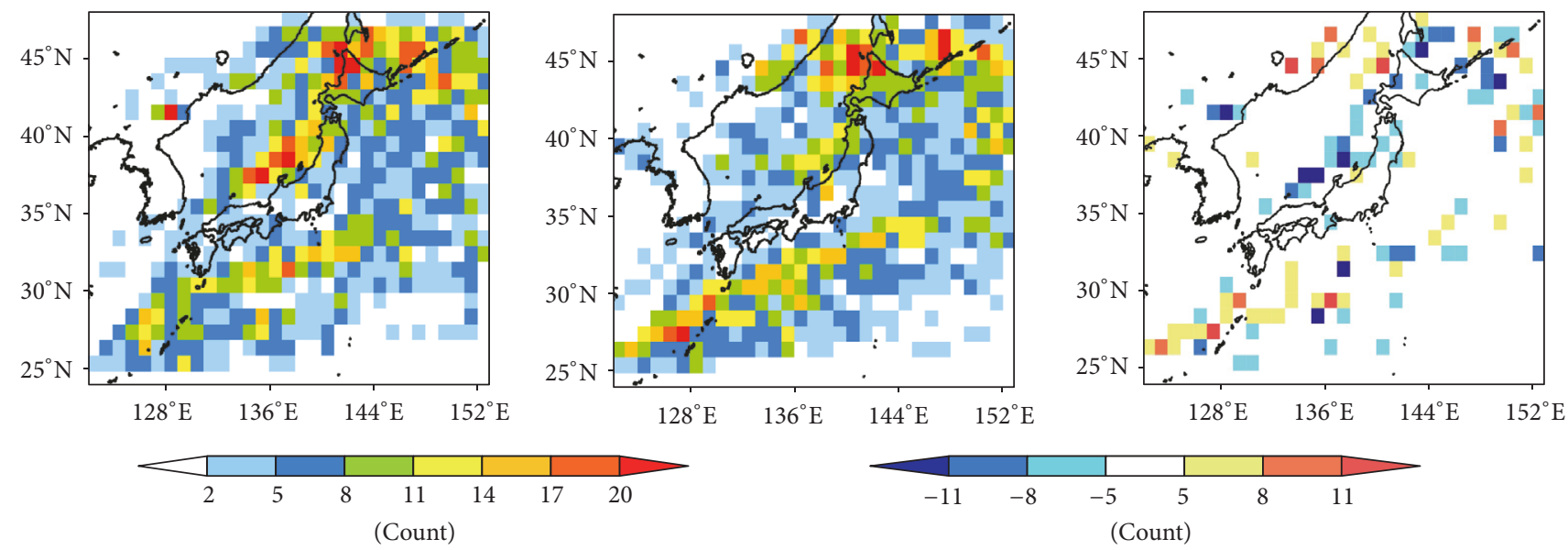

(a) CTL run

(b) MOD run

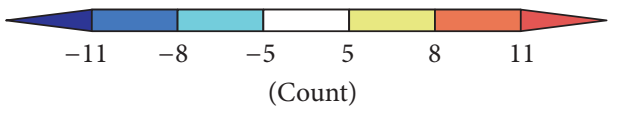

(c) Difference

FIGURE 4: (a) Frequency distribution of synoptic-scale cyclone tracks during 2000-2014 for the CTL run. (b) As in Figure 4(a) but for the MOD run. (c) Difference in cyclone track frequency between the MOD and CTL runs (former minus latter).

MOD runs and its difference map between the two runs. In this study, the EGR is evaluated for the layer between the 950 and $700 \mathrm{hPa}$ levels as follows:

$$
\mathrm{EGR}=0.31\left(\frac{f}{N}\right)\left|\frac{\partial u}{\partial z}\right|
$$

where $f$ is the Coriolis parameter, $N$ is the Brunt-Vaisala frequency, and $\partial u / \partial z$ is the zonal wind vertical shear. The EGR is determined by static stability and vertical wind shear, which is useful as an appropriate measure of lower-tropospheric baroclinicity. Looking at Figure 3, the maximum areas of EGR in excess of 1.0 day $^{-1}$ are located over the Japan Sea and the Kuroshio-Oyashio confluence region in the CTL run. This feature is similar to the results of Hayasaki and Kawamura [20] and Iizuka et al. [5]. As already introduced in Section 1, the area characterized by high EGR values over the Japan Sea is hereafter called the lower-tropospheric baroclinic zone (LTBZ). In contrast, the EGR in the MOD run is remarkably reduced over the Japan Sea. As a consequence, large EGR differences can be seen in the areas downstream of the Changbai Mountain Range, implying that the formation of the LTBZ is attributable mainly to the Changbai Mountain. The EGR differences seen in Figure 3(c) satisfy the 95\% confidence level. We thus expect that this mountain range exerts an influence on the activity of synoptic-scale cyclones that occur and/or develop over the Japan Sea.

3.2. Synoptic-Scale Cyclone Activity. To clarify the change in the synoptic-scale cyclone activity, we focus specifically on three appropriate measures: cyclone track frequency, lowlevel poleward heat flux associated with synoptic eddies, and the local deepening rate of surface pressure. Figure 4 indicates the frequency distribution of cyclone tracks in December for the CTL and MOD runs and its difference between the two runs. In the CTL run, the major cyclone tracks in the vicinity of Japan tend to concentrate in the Kuroshio and the Japan Sea, which is consistent with the results of Shou-Jun Chen et al. [2], Yoshiike and Kawamura [4], Iizuka et al. [5], and so on. In the MOD run, on the other hand, the cyclone track frequency becomes low along the Japan Sea coast of Japan. Indeed, the frequency difference (Figure 4(c)) appears along these coastal areas. As we know, however, different tracking methods may yield different results. Thus, we need to validate whether such a change is robust using alternative measures.

Figure 5(a) shows the difference in poleward eddy heat flux at $850 \mathrm{hPa}$ in December between the MOD and CTL runs (former minus latter). Here, the poleward eddy heat flux is defined as $v^{\prime} T^{\prime}$, where $v$ is the meridional wind, $T$ is temperature, and a prime designates subweekly fluctuations in $v$ and $T$. The subweekly fluctuations (or synoptic timescale variations) are extracted by applying a simple combination of two low-pass filters (2-day running average and 8-day running average) to the 3-hourly model output data. Noticeable differences are indicated near the LTBZ in the central Japan Sea. This implies that the $850 \mathrm{hPa}$ poleward eddy heat flux in the MOD run is weaker than that in the CTL run, which is consistent with the weakened LTBZ seen in the MOD run. It seems that the influence of the Changbai Mountain on the storm-track activity in the lower troposphere is confined within the Japan Sea. Figure 5(b) presents the difference in the local deepening rate (LDR) in December between the MOD and CTL runs (former minus latter). Following the criteria of Kuwano-Yoshida [22], LDR is defined to assess the synopticscale cyclone activity as follows:

$$
\mathrm{LDR}=-\frac{p(t+12 h)-p(t-12 h)}{24}\left|\frac{\sin 60^{\circ}}{\sin \theta}\right|,
$$

where $p$ is the surface pressure, $t$ is the time in hours, and $\theta$ is the latitude of the grid point. Kuwano-Yoshida [22] emphasized that the LDR can capture not only an individual extratropical cyclone's deepening but also the midlatitude storm-track activity. This study uses the total value of the positive LDR over a month to compare the two runs. Similarly, significant LDR differences can be seen around the areas downstream of the Changbai Mountain, indicating 


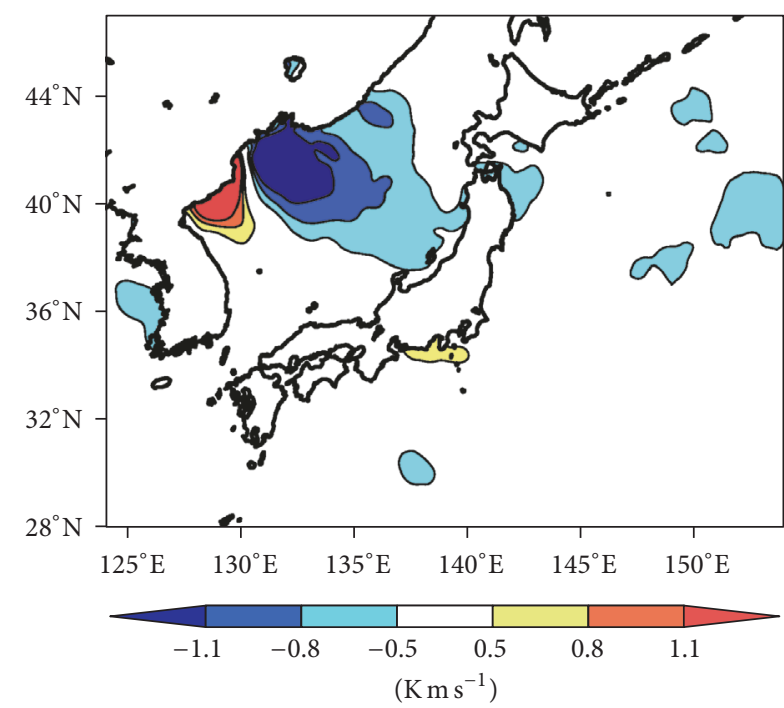

(a) Eddy heat flux

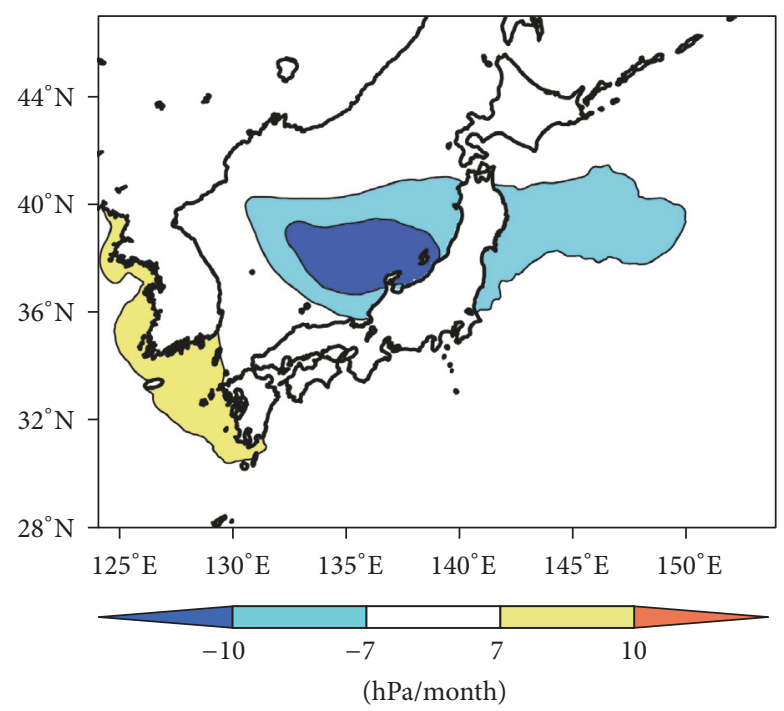

(b) LDR

Figure 5: (a) Difference in the $850 \mathrm{hPa}$ poleward eddy heat flux for December between the MOD and CTL runs (former minus latter). The shading interval is $0.3 \mathrm{~K} \mathrm{~m} \mathrm{~s}^{-1}$. (b) As in Figure 5(a) but for the local deepening rate (LDR). Shading interval is $3 \mathrm{hPa} / \mathrm{month}$.

the weakening of cyclone activity over the Japan Sea in the MOD run. This feature is consistent with the change in the cyclone track frequency, as shown in Figure 4(c). The largest difference in LDR does not necessarily coincide with the largest difference in EGR (Figure 3(c)). According to Kuwano-Yoshida [22], LDR includes the effects of cyclone development and expansion of the deepening area, which may result in such a difference.

The aforementioned three measures consistently exhibit the inhibition of synoptic-scale cyclone activity over the Japan Sea in the MOD run in association with weakened baroclinicity in the lower troposphere. Thus, we would like to stress that the Changbai Mountain plays a vital role not only in the JPCZ formation but also in the activity of wintertime synoptic-scale cyclones over the Japan Sea in climate terms. However, it is still uncertain how the orographic effects induced by the Changbai Mountain dynamically modulate individual cyclones. In the next section, we highlight several typical cases and inspect such dynamical modulations by carrying out independent simulations.

\section{Individual Cyclone Cases}

We selected three cyclones that passed over the Japan Sea as typical cases. Figure 6 shows the tracks of those cyclones, together with the topography and climatological mean $925 \mathrm{hPa}$ horizontal wind divergence for December. It is noteworthy that these three rapidly developing cyclones satisfy the criterion for an explosive cyclone as defined by Yoshiike and Kawamura [4]. A distinctive low-level convergence zone between the Changbai Mountain and the Japan Sea coast of central Japan is a climatological manifestation of the JPCZ. The initial appearance of the three cyclones is about 13:00 UTC on December 4, 2012, for case 1; 17:00 UTC on December 6, 2012, for case 2; and 01:00 UTC on December 27,
2009, for case 3. A common feature of cases 1 and 2 is that the cyclones passed across the Korean Peninsula and developed rapidly over the Japan Sea, but case 1 (case 2) migrated over the northwestern (southeastern) side of the climatological JPCZ. The cyclone in case 3 was generated in the vicinity of the climatological JPCZ and migrated northward over the Japan Sea with rapid growth. We performed the CTL and MOD runs with regard to these cyclones under the same design as the numerical experiments in Section 2, except that we adjusted only the initial time and integration time for each case. We also compared the results of the CTL run and the Japanese 55-year Reanalysis (Kobayashi et al. [23]) data and confirmed that, for all cases, the overall features of cyclone development were successfully reproduced in the WRF-ARW model.

4.1. Differences in Cyclone Development and Structure. Figure 7 shows the time evolutions of SLP, $850 \mathrm{hPa}$ relative vorticity, and horizontal wind simulated by the CTL and MOD runs for case 1. In the CTL run, the cyclone develops rapidly and migrates northeastward over the Japan Sea. Corresponding to the cyclone's development, the low-level relative vorticity distributions exhibit a typical T-bone structure composed of a bent-back front, warm front, and cold front, which is very similar to the Shapiro-Keyser model (Shapiro and Keyser [24]). At 14:00 UTC on December 5, a minimum SLP area around the bent-back front of the cyclone is located in the region of a monsoon flow confluence on the downstream side of the Changbai Mountain. This confluence region is characterized by northerlies to the east of the mountain and westerlies to its south. The mesoscale eddy near the bent-back front is further enhanced with the cyclone's development, and a twin eddy structure becomes pronounced in the vicinity of the cyclone center at 19:00 UTC on December 5. In the MOD run, on the other hand, a confluence region is absent 


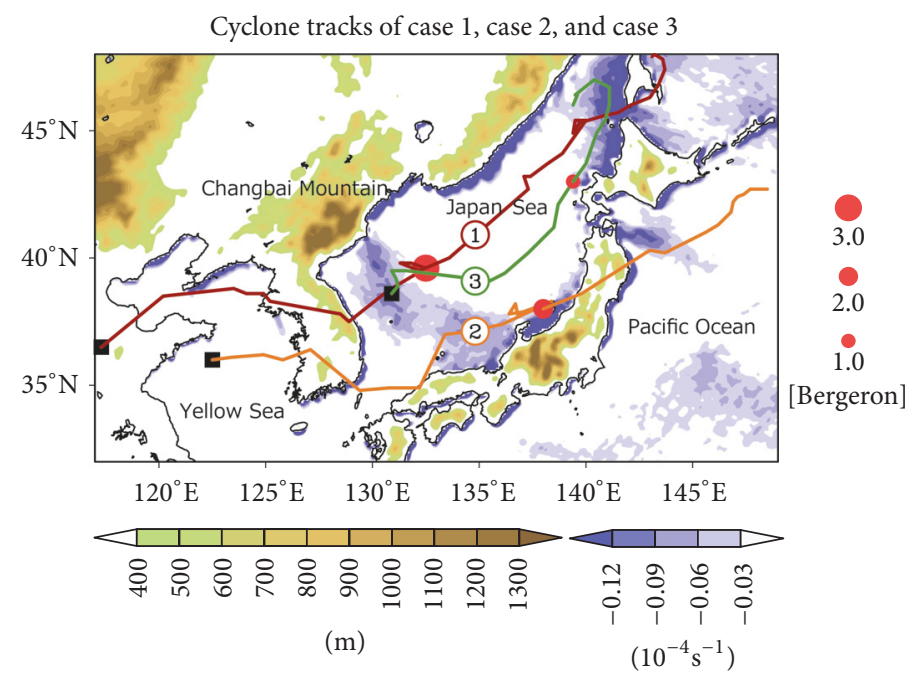

Figure 6: Tracks of the three synoptic-scale cyclones extracted as typical cases. The location of the initial appearance of a cyclone is denoted by blue rectangles. The locations of explosive cyclones when their rates of development reached the maximum are indicated by red circles. The size of the circles denotes the magnitude of the maximum deepening rate $\left(\mathrm{hPa} \mathrm{hr}^{-1}\right)$. The topography and climatological mean $925 \mathrm{hPa}$ horizontal wind divergence for December are also shown. The shading interval for wind divergence is $3 \times 10^{-6} \mathrm{~s}^{-1}$.

at 14:00 UTC on December 5. Associated with this absence, a minimum SLP area shifts eastward and is located near the northern edge of the cold front. After that, although the cyclone develops, the configuration of the cyclone center is relatively axisymmetric as compared to the CTL run, and the twin eddy structure is obscure at 19:00 UTC on December 5. These features suggest that the Changbai Mountain Range gives rise to the deformation of the cyclone center through the generation and reinforcement of a mesoscale eddy in a confluence region on the downstream side of the mountain range.

In a similar fashion, the time evolutions of SLP, $850 \mathrm{hPa}$ relative vorticity, and horizontal wind simulated by the CTL and MOD runs for case 2 are presented in Figure 8. In the CTL run, 22:00 UTC on December 7 corresponds to the time just after the cyclone center of case 2 passes across the climatological JPCZ. At this time, a low-level shear line is well organized over the central Japan Sea. In the MOD run, in contrast, such a shear line is absent, and the cyclone center is also less clear. Subsequently, the minimum SLP area seen in the CTL run moves across northern Japan and further expands at 10:00 UTC on December 8, whereas in the MOD run, the central pressure of the cyclone is considerably high at the same time. Thus, the difference in the central pressure of the cyclone at its developing and mature stages is evident for case 2 .

Figure 9 is the same as Figures 7 and 8 but for case 3. In the CTL run, a salient shear line in the lower troposphere is established on the downstream side of the Changbai Mountain Range at 05:00 UTC on December 27, and a minimum SLP area appears on the eastern edge of the shear line, accompanied by a surface trough. After that time, the eddy characterized by the SLP minimum rapidly expands and migrates northeastward, consequently separating from the shear line. At 19:00 UTC on December 27, the enhanced eddy is identified with a synoptic-scale cyclone and further grows to the west of northern Japan. However, the MOD run cannot reproduce such a cyclogenesis in conjunction with a surface trough and low-level shear line.

We focused specifically on the lower-tropospheric circulation fields and found that the Changbai Mountain Range, indeed, dynamically modulates the synoptic-scale cyclones in all three cases in terms of the deformation of the cyclone's configuration, the cyclone's development, and the cyclogenesis. It is also noteworthy that the differences in the upper tropospheric circulation fields between the CTL and MOD runs are quite small in all three cases (not shown). This suggests that the orographic effect is confined to the lower troposphere in these cases.

4.2. Vorticity Budget Analysis. To further explore what dynamic processes contribute to the enhanced low-level vorticity in the cyclone center, we made a vorticity budget analysis at the $850 \mathrm{hPa}$ level. The vorticity tendency equation is given as follows:

$$
\begin{aligned}
\frac{\partial \zeta}{\partial t}= & -\mathbf{V} \cdot \nabla(\zeta+f)-\omega \frac{\partial \zeta}{\partial p}-(\zeta+f) \nabla \cdot \mathbf{V}+\mathbf{k} \\
& \cdot\left(\frac{\partial \mathbf{V}}{\partial p} \times \nabla \omega\right)
\end{aligned}
$$

where $\zeta$ is the relative vorticity, $f$ is the planetary vorticity, $\mathrm{V}$ is the horizontal wind vector, and $\omega$ is the vertical $p$ velocity. Figure 10 reveals the vorticity tendency, each budget term, and the sum of all terms on the right side of the equation in the CTL run for case 2. The time is 17:00 UTC on December 7, 2012, when an eddy grows rapidly in the vicinity of the cyclone center. The spatial distribution of the 


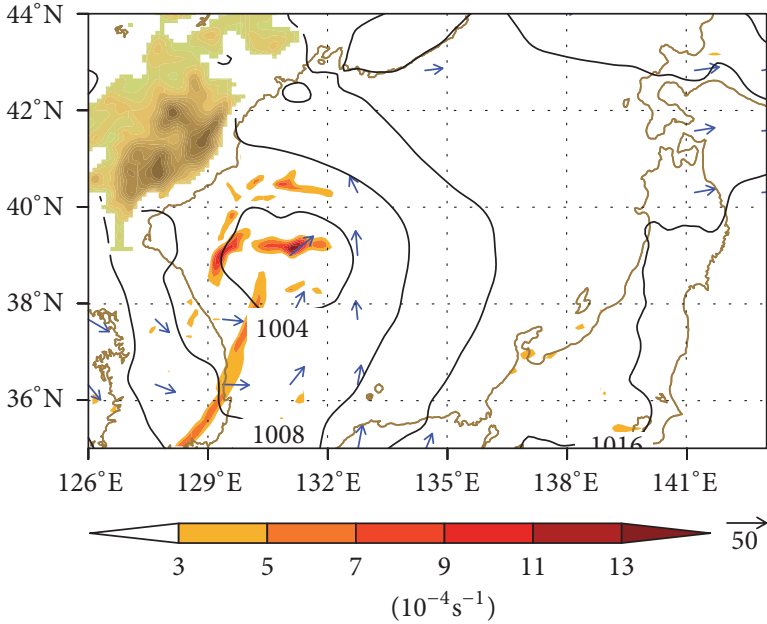

(a) CTL run 10:00 UTC 5 Dec

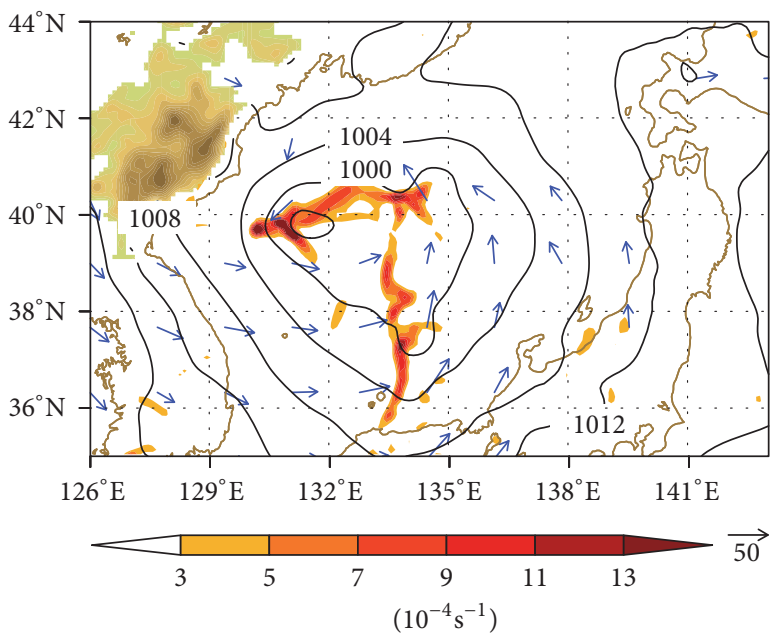

(b) CTL run 14:00 UTC 5 Dec

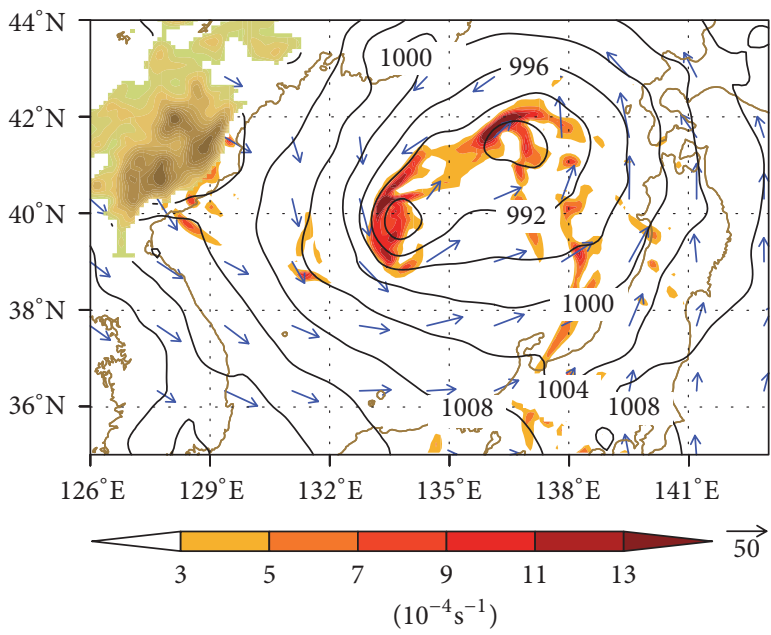

(c) CTL run 19:00 UTC 5 Dec

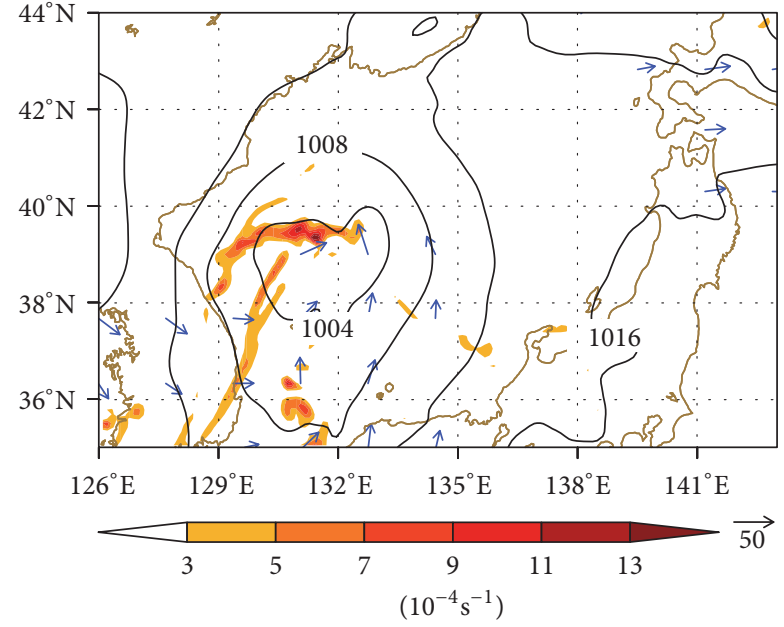

(d) MOD run 10:00 UTC 5 Dec

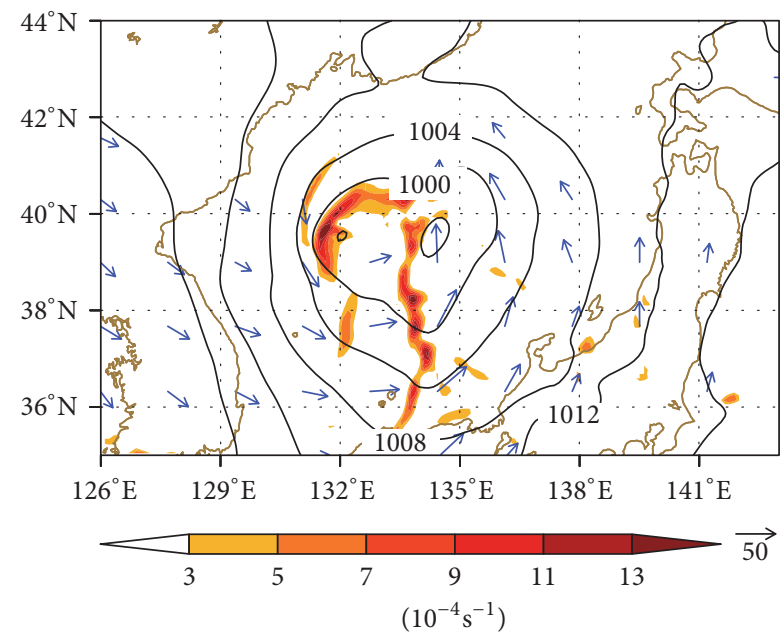

(e) MOD run 14:00 UTC 5 Dec

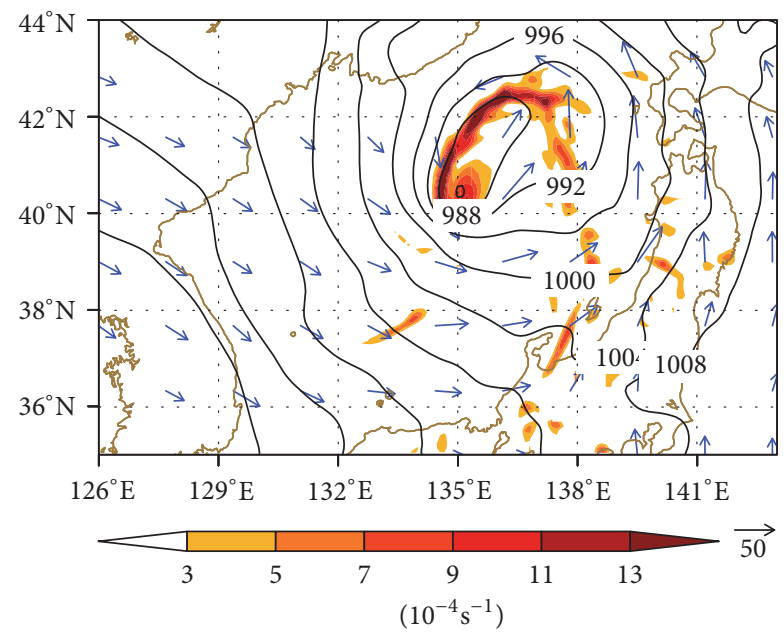

(f) MOD run 19:00 UTC 5 Dec

FIGURE 7: $(\mathrm{a}-\mathrm{c}$ ) Time evolutions of SLP (contours), $850 \mathrm{hPa}$ relative vorticity (shaded), and $850 \mathrm{hPa}$ horizontal wind (vectors) in the CTL run for case 1 . The contoured interval is $4 \mathrm{hPa}$. The shading interval is $2 \times 10^{-4} \mathrm{~s}^{-1}$. The reference arrow is $50 \mathrm{~m} \mathrm{~s}^{-1}$. Wind speeds less than $15 \mathrm{~m} \mathrm{~s}^{-1}$ are suppressed. $(\mathrm{d}-\mathrm{f})$ As in $(\mathrm{a}-\mathrm{c})$ but for the MOD run. 


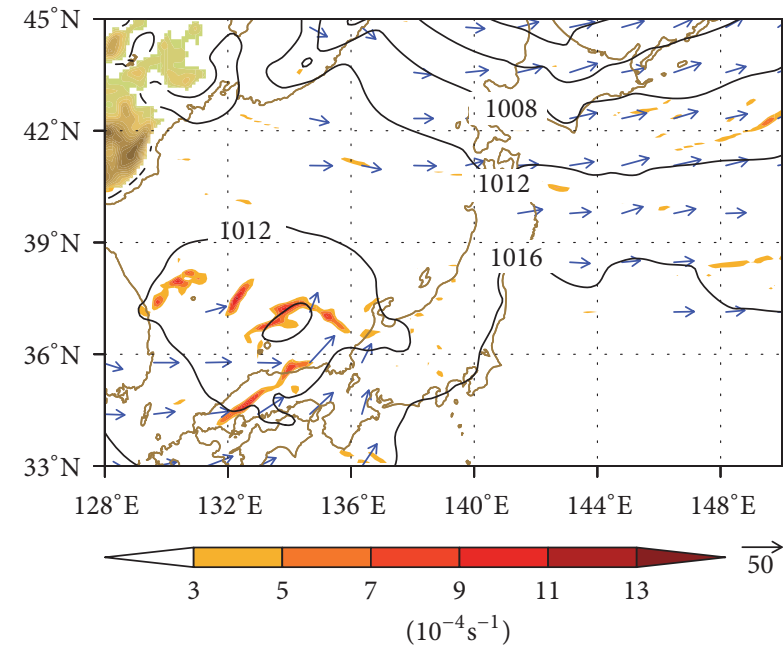

(a) CTL run 10:00 UTC 7 Dec
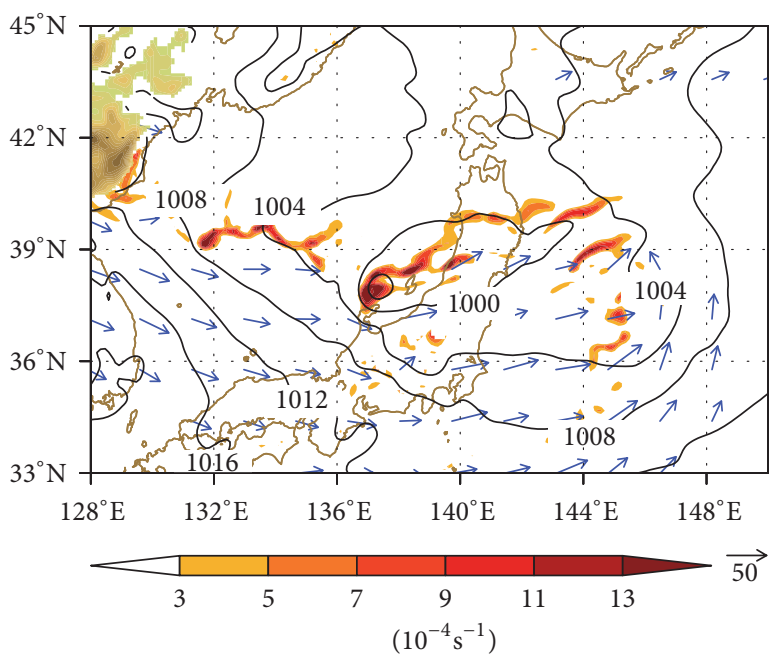

(b) CTL run 22:00 UTC 7 Dec
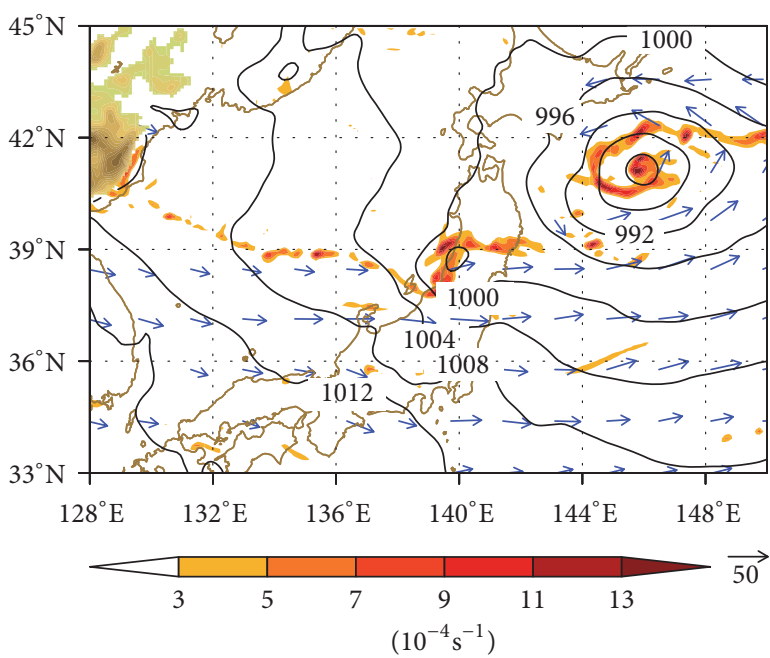

(c) CTL run 10:00 UTC 8 Dec

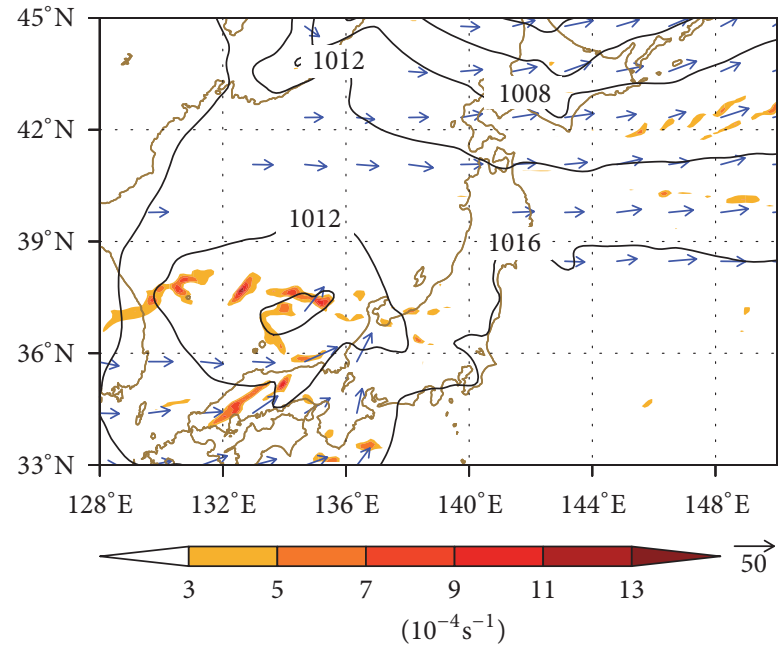

(d) MOD run 10:00 UTC 7 Dec
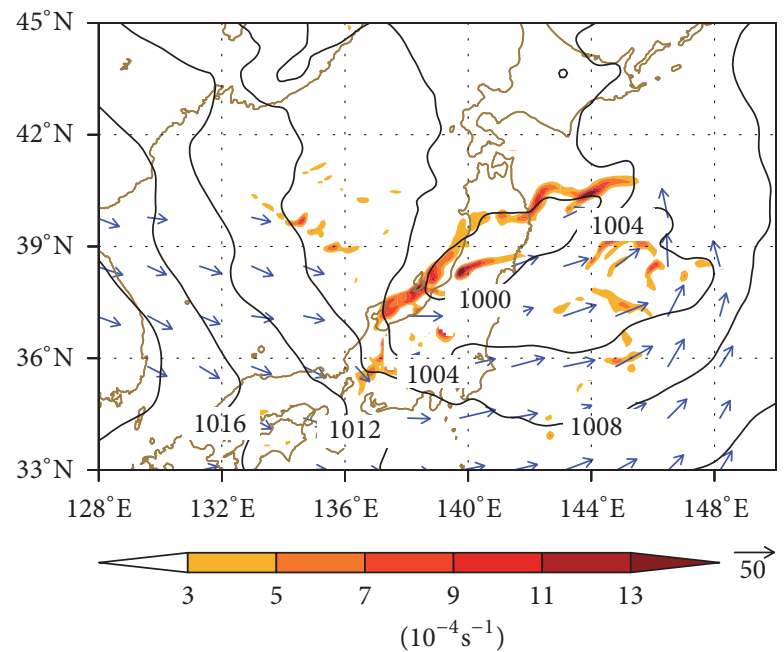

(e) MOD run 22:00 UTC 7 Dec
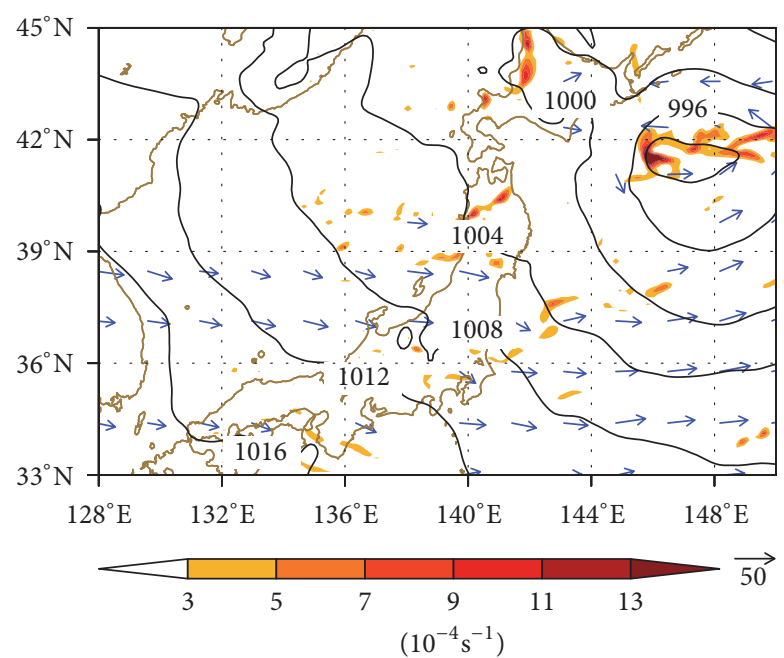

(f) MOD run 10:00 UTC 8 Dec

Figure 8: As in Figure 7 but for case 2. 


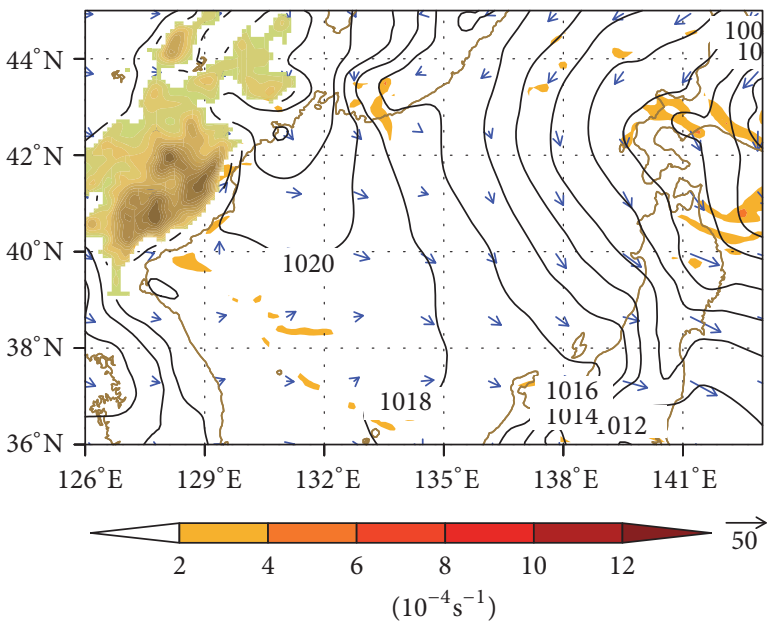

(a) CTL run 21:00 UTC 26 Dec

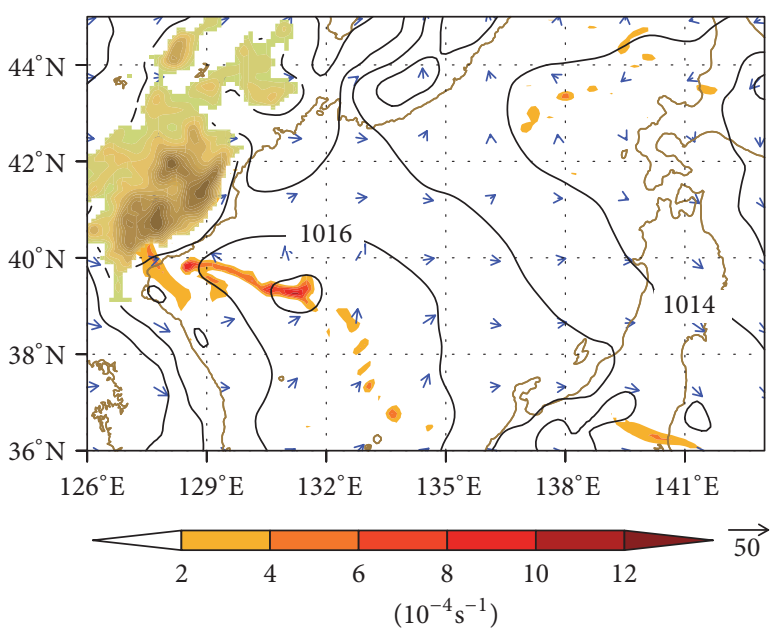

(b) CTL run 05:00 UTC 27 Dec

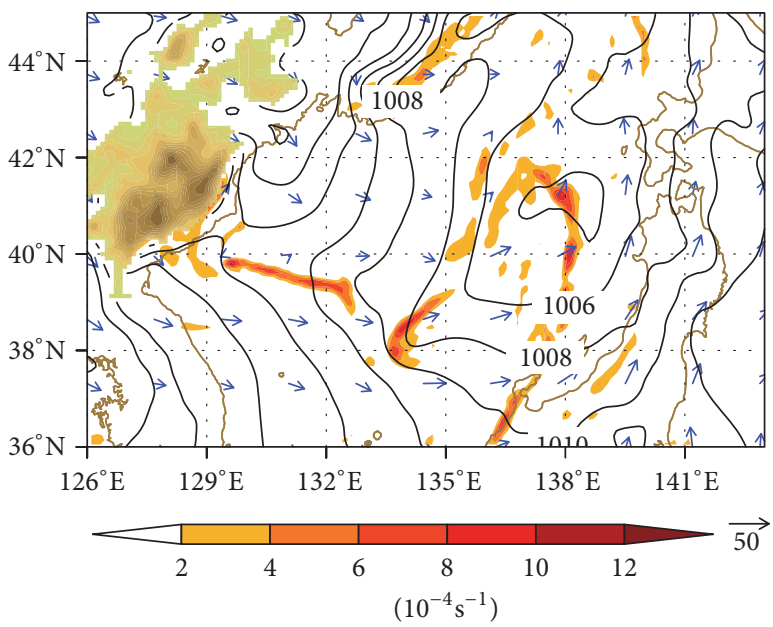

(c) CTL run 19:00 UTC 27 Dec

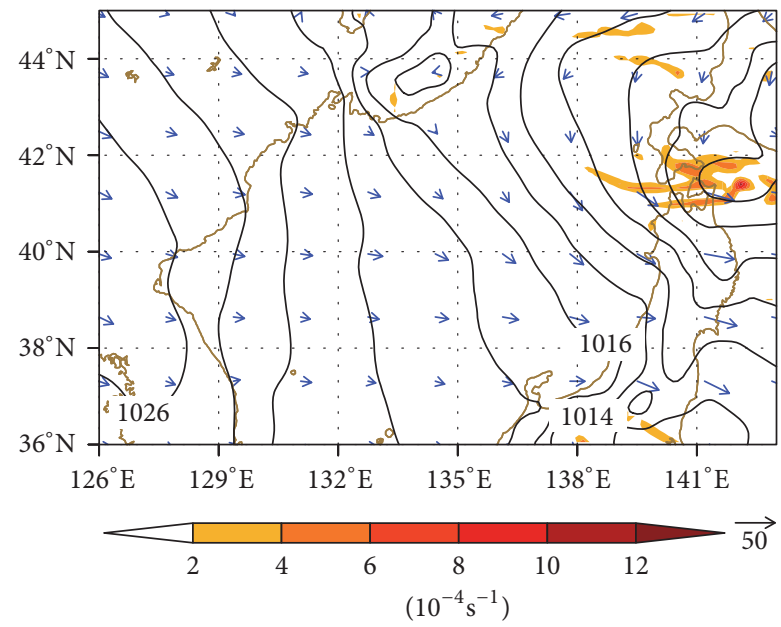

(d) MOD run 21:00 UTC 26 Dec

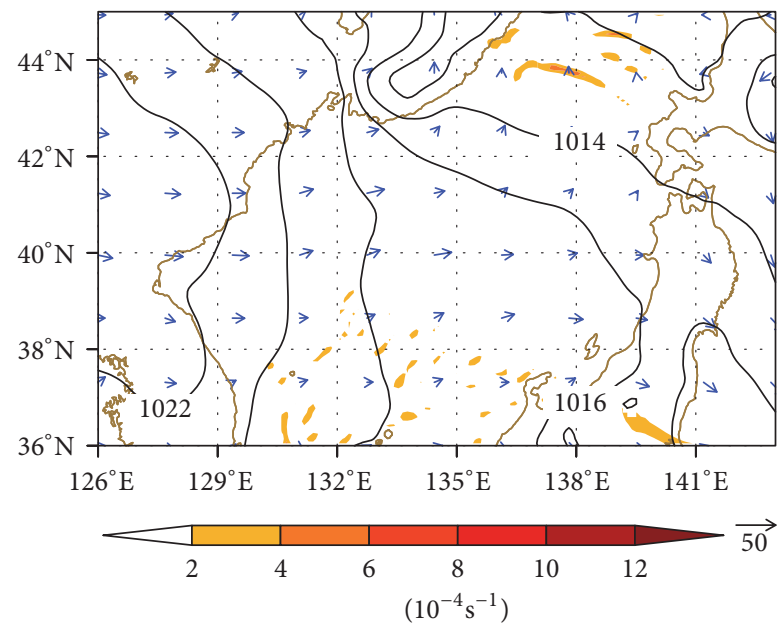

(e) MOD run 05:00 UTC 27 Dec

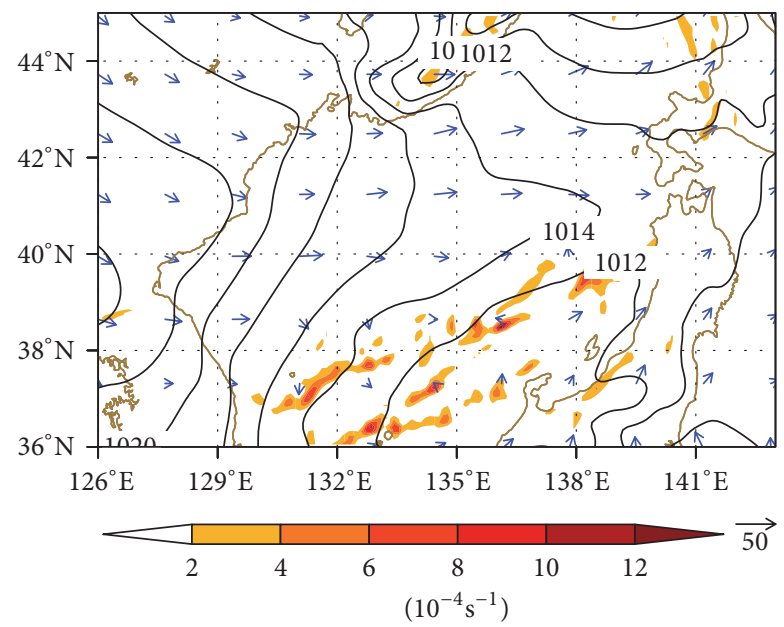

(f) MOD run 19:00 UTC 27 Dec

Figure 9: As in Figure 7 but for case 3. 


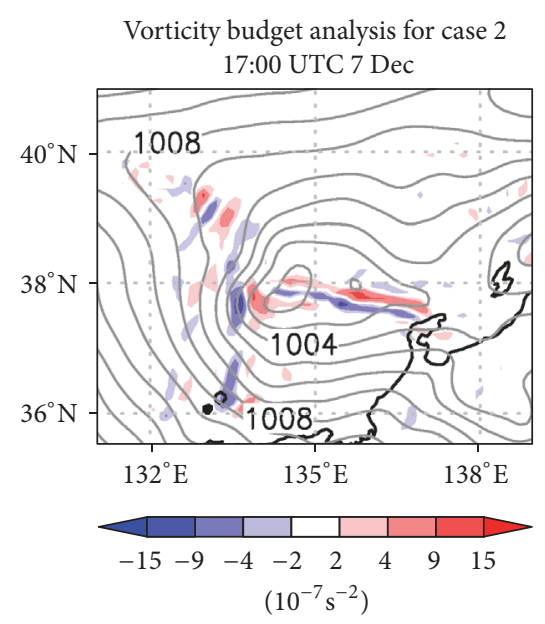

(a) Tendency

Vorticity budget analysis for case 2 17:00 UTC 7 Dec

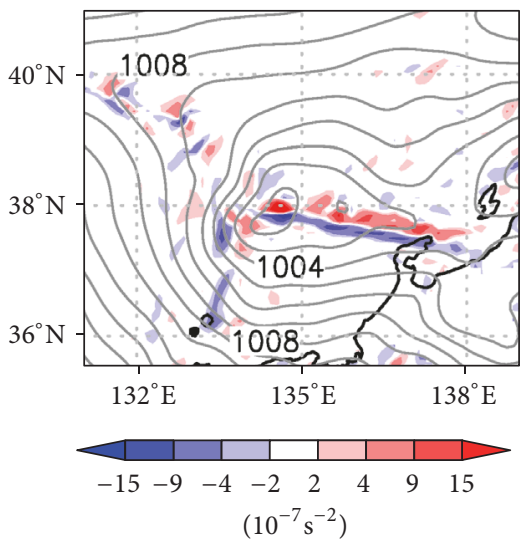

(d) Sum of all terms

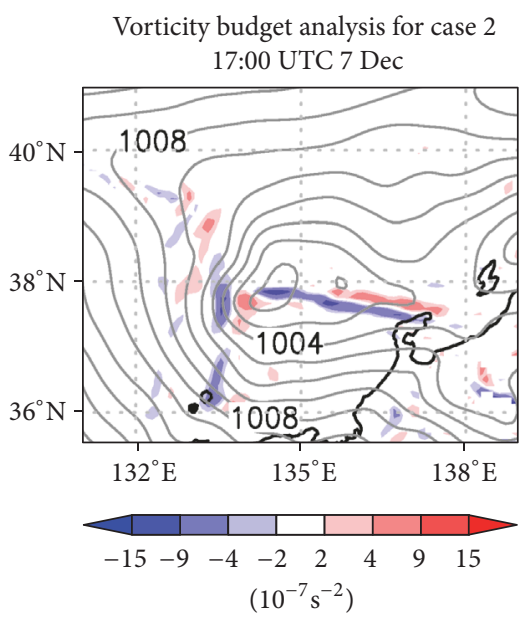

(b) Horizontal advection

Vorticity budget analysis for case 2 17:00 UTC 7 Dec

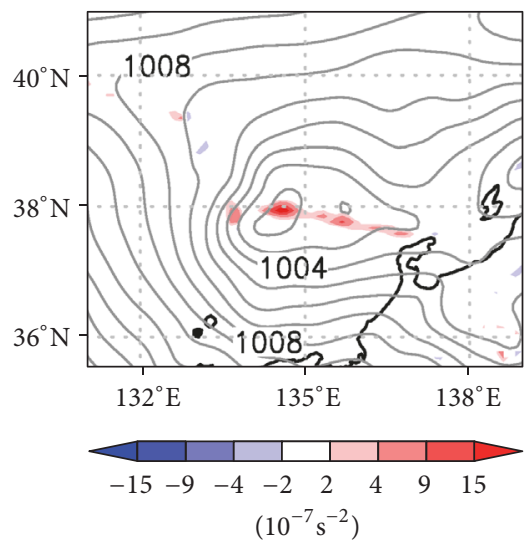

(e) Stretching

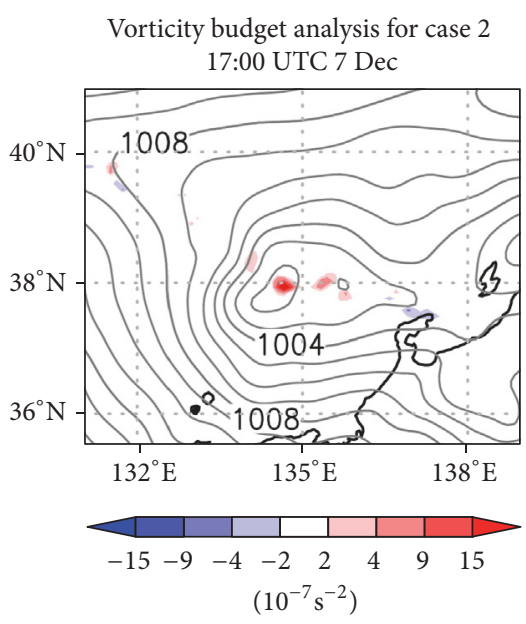

(c) Vertical advection

Vorticity budget analysis for case 2 17:00 UTC 7 Dec

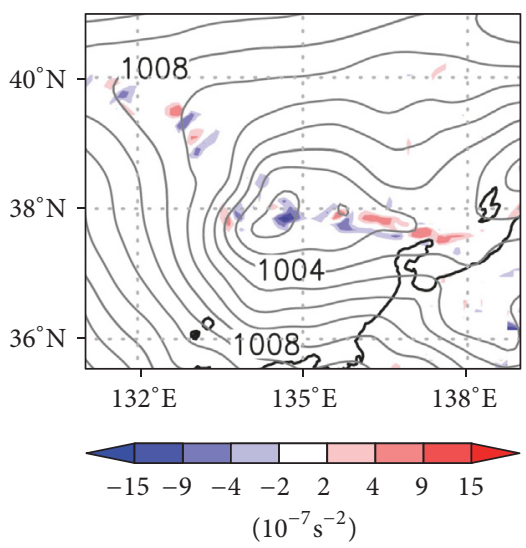

(f) Tilting

FIgURE 10: Results of the vorticity budget analysis in the CTL run for case 2. The selected time is 17:00 UTC on December 7. The shading denotes the spatial distributions of vorticity tendency, each budget term, and the sum of the budget terms. The SLP distribution at that time is also shown.

sum of all terms (Figure 10(d)) coincides comparatively well with that of the vorticity tendency. An immediate indication is that the horizontal advection term plays a dominant role in the distribution of the vorticity tendency. This feature is obvious because the cyclone system moves horizontally with time. Here, notable terms are the vortex stretching and the tilting terms that induce the vorticity. It turns out that the stretching term is directly responsible for a positive vorticity tendency that extends zonally around the cyclone center, whereas the tilting term is minor. We also confirmed that the stretching term in the MOD run is smaller than that in the CTL run (not shown). In addition, the vorticity budget analyses have been done for case 1 and case 3, and consistent results were derived. These results indicate that the Changbai Mountain Range contributes a great deal to the generation of a cyclonic vorticity anomaly in the cyclone system through the reinforcement of low-level wind convergence.

\section{Discussion}

5.1. Composite Features of the Three Typical Cases. Both climatological analyses and case studies strongly suggest that the presence of the Changbai Mountain Range leads to the activation of synoptic-scale cyclone activity over the Japan Sea in December. However, one might wonder if the dynamical modulation of the cyclones seen in the typical cases can indeed account for the changes in cyclone activity in climate terms between the CTL and MOD runs. Since we do not think it easy to simulate all individual cyclones that existed over the Japan Sea during the 15 winter months, we present here composite features of the aforementioned three typical cases.

Figure 11 shows the composite differences in the $850 \mathrm{hPa}$ poleward eddy heat flux and the LDR between the MOD and CTL runs (former minus latter) based on the three cases. It should be noted here that we calculate the daily averages of the variables from $t=-12$ to $12 \mathrm{~h}$ on the basis of the 


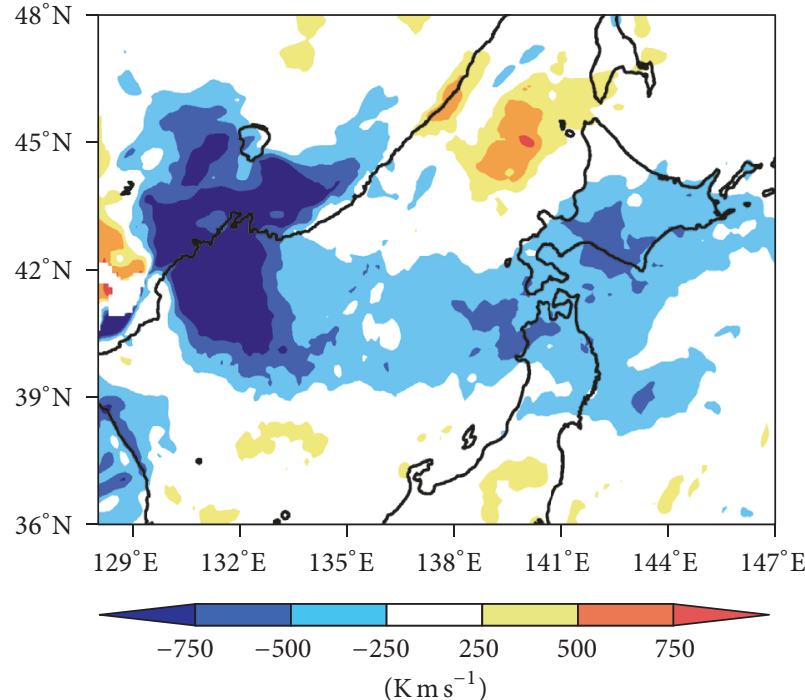

(a) Eddy heat flux

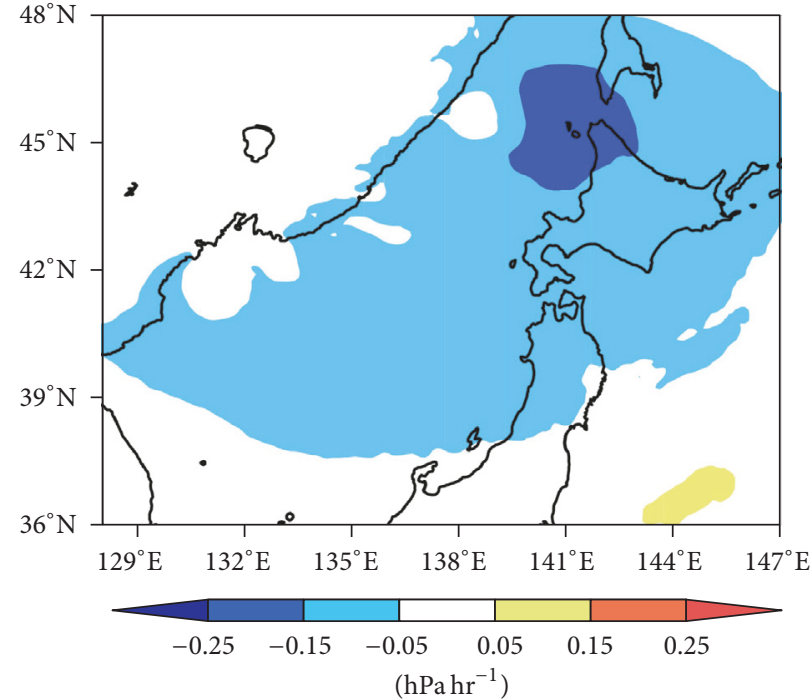

(b) LDR

FIGURE 11: (a) Composite differences in the $850 \mathrm{hPa}$ poleward eddy heat flux between the MOD and CTL runs (former minus latter) based on the three typical cases. The shading interval is $250 \mathrm{~K} \mathrm{~m} \mathrm{~s}^{-1}$. (b) As in Figure 11(a) but for the local deepening rate (LDR). The shading interval is $0.1 \mathrm{hPa} \mathrm{hr}^{-1}$.

time $(t=0 \mathrm{~h})$ when the center of the cyclone in each case passes through $136^{\circ} \mathrm{E}$ in the central Japan Sea and make composite maps of the three cases. A large difference in the $850 \mathrm{hPa}$ poleward eddy heat flux between the two runs extends zonally over the area downstream of the Changbai Mountain, implying the decreased storm-track activity in the MOD run. The LDR in the MOD run also tends to be lower over the central and northern Japan Sea than that in the CTL run. These two measures exhibit the suppression in synopticscale cyclone activity in the MOD run, which is similar to the results of Figure 5, although, of course, the sample number is very small for the composite analyses. Thus, we infer that part of all cyclones that occurred and/or developed over the Japan Sea during the 15 winter months is dynamically modulated by the Changbai Mountain, as in the three typical cases. If we carry out many more independent simulations with regard to the other cyclones, composite difference maps of the above two measures of the cyclone activity would be very close to the features of Figure 5.

5.2. Subpolar Front over the Japan Sea. According to the smoothed SST experiment of Iizuka et al. [5], the geographical concentration in the explosive cyclone activity over the Japan Sea tends to weaken. This may mean that the Japan Sea subpolar front plays an influential role in its concentration. Thus, we conducted a similar smoothed SST experiment (hereafter called the SS run) to examine the relative importance of the subpolar front in the Japan Sea and the Changbai Mountain in the cyclone activity. Figure 12 shows the spatial distributions of SST averaged over 15 winter months (December only) from 2000 to 2014 for the CTL and SS runs. Sharp SST gradients over the central Japan Sea in the CTL run, which correspond to the subpolar front, become considerably weak in the SS run. Note that the SS run is performed without modified topography.

Figure 13 reveals the climatological mean monthly precipitation in December for the SS run, based on the 15-year period from 2000 to 2014, and its difference between the SS and CTL runs (former minus latter). Small differences in precipitation are seen in the vicinity of the JPCZ and in the coastal regions of central and northern Japan, as compared to those in Figure 2(c). This result implies the weakening of the JPCZ, which is consistent with the findings of Nagata et al. [7] and Nagata $[8,9]$. Figure 14 shows the differences in cyclone track frequency, the $850 \mathrm{hPa}$ poleward eddy heat flux, and the LDR between the SS and CTL runs (former minus latter). No systematic differences can be seen for the three measures of cyclone activity, and the magnitudes of the differences are very small as compared to those between the MOD and CTL runs. Thus, it seems that the effect of the Japan Sea subpolar front is minor with regard to synoptic-scale cyclone activity. One may argue that our results are in contradiction with those of Iizuka et al. [5]. Since they discussed the passive role of the SST front in explosive cyclone activity at the strong winter monsoon phase during the winter season (December to February), it should be noted that a simple comparison between the two studies is difficult. In addition, the SST distribution in their smoothed SST run is smoothed for the whole domain, including the East China Sea and the Kuroshio/Kuroshio Extension, whereas the smoothing procedure in our SS run applies only to the Japan Sea SST. Thus, the SST front in the East China Sea might be more important in the concentration of explosive cyclone activity over the Japan Sea than the subpolar front. 


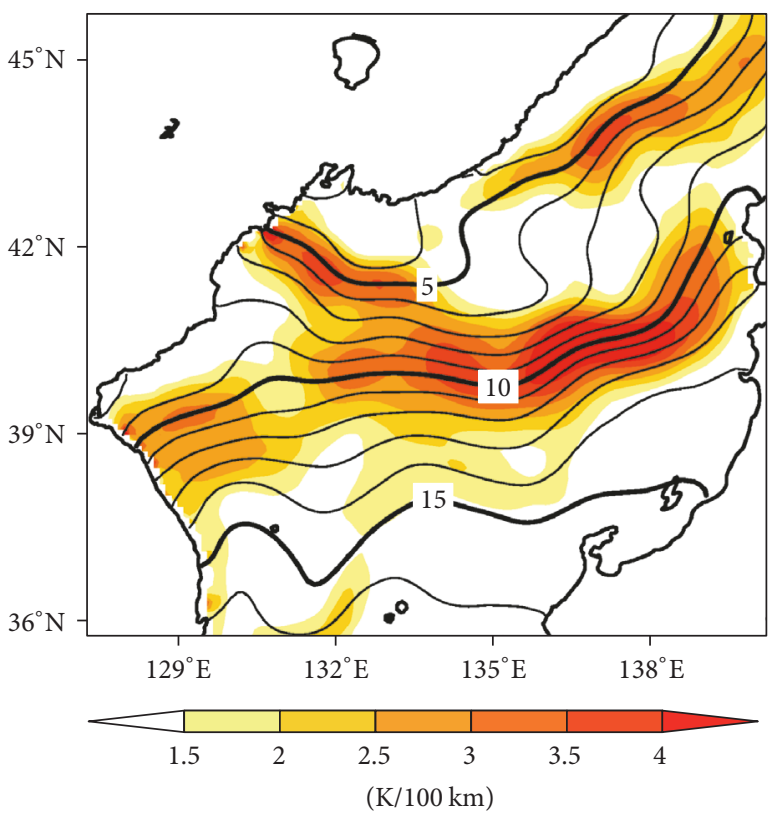

(a) CTL run

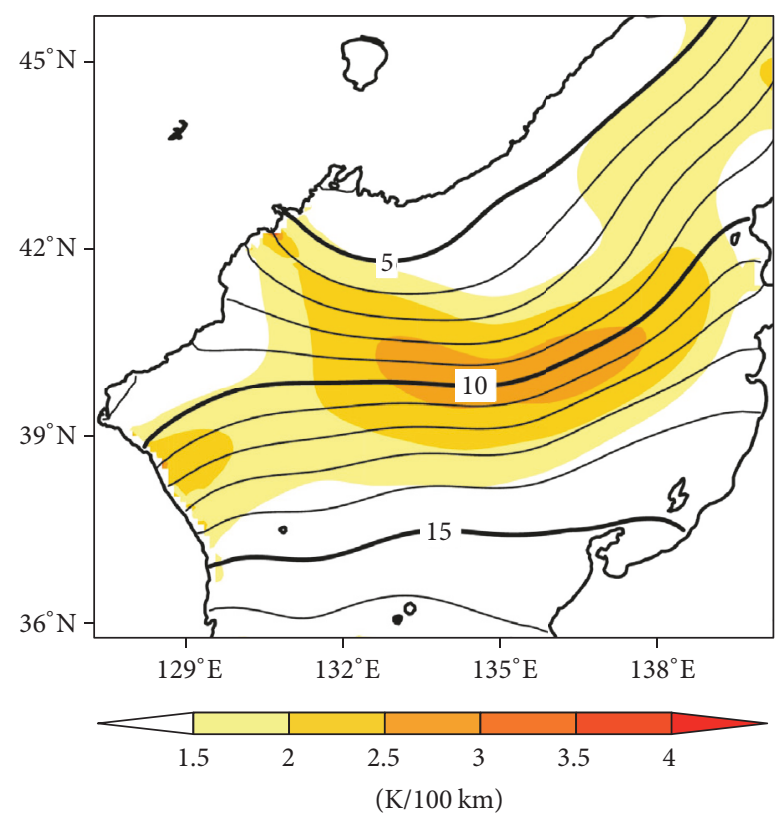

(b) SS run

FIGURE 12: (a) Spatial distribution of OISST averaged over the period of 2000-2014. The contoured interval is $1 \mathrm{~K}$. The shading denotes the horizontal SST gradient (K/100 km). (b) As in Figure 12(a) but for horizontally smoothed OISST.

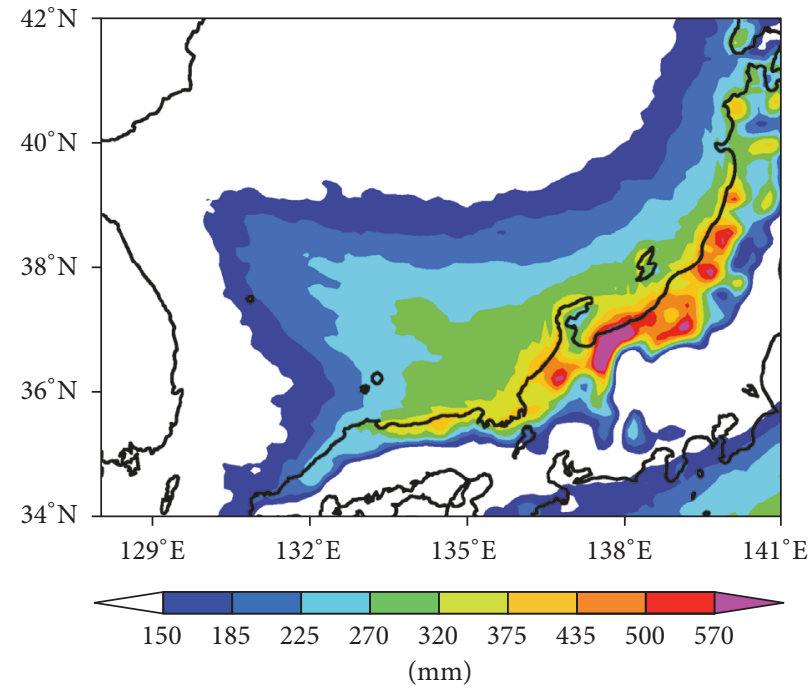

(a) SS run

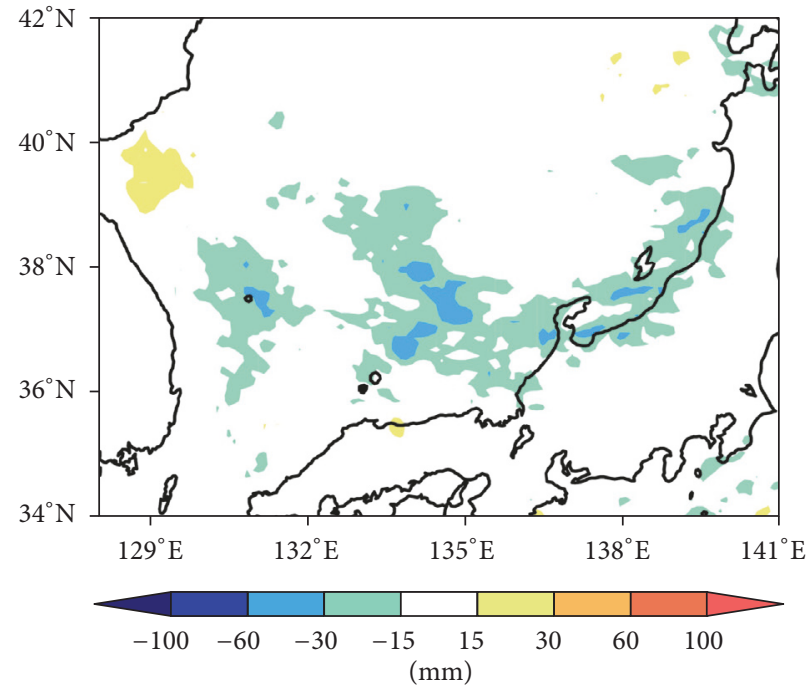

(b) SS run minus CTL run

FIGURE 13: (a) Climatological mean December precipitation during 2000-2014 for the SS run. (b) Difference in precipitation between the SS and CTL runs (former minus latter).

\section{Summary}

We carried out numerical simulations with and without modified topography in the Korean Peninsula using a regional atmospheric model to investigate the dynamical impact of the Changbai Mountain Range on wintertime synoptic-scale cyclone activity over the Japan Sea, especially in early winter.

Comparing the experiments with and without modified topography (the MOD and CTL runs), the attenuation of the Japan Sea polar air mass convergence zone (JPCZ) in climate terms is simulated by the MOD run. The MOD run also exhibits decreases in the cyclone track frequency, the $850 \mathrm{hPa}$ poleward eddy heat flux, and the local deepening rate (LDR), which are appropriate measures of synoptic-scale cyclone activity, in the regions downstream of the Changbai Mountain, concurrent with the weakened lower-tropospheric baroclinic zone (LTBZ). We find that the Changbai Mountain Range leads to not only the JPCZ formation but also the 


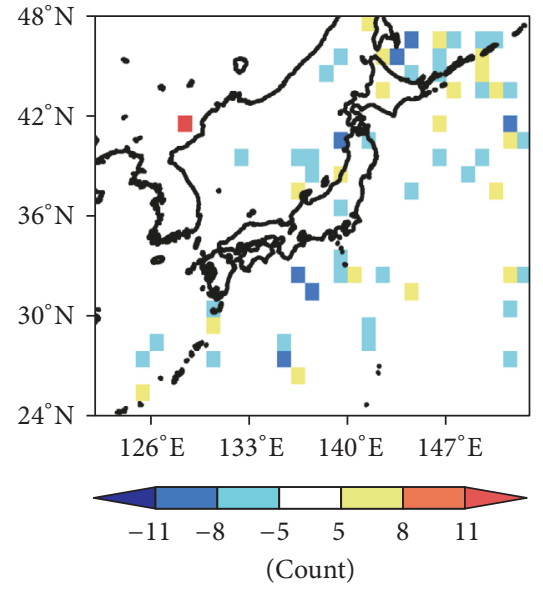

(a) Cyclone track

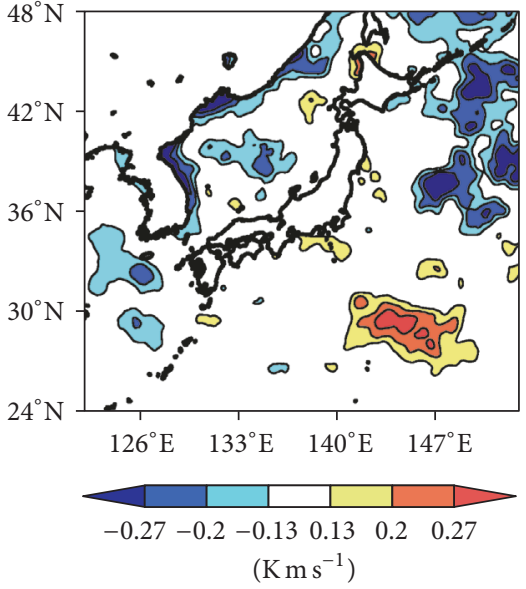

(b) Eddy heat flux

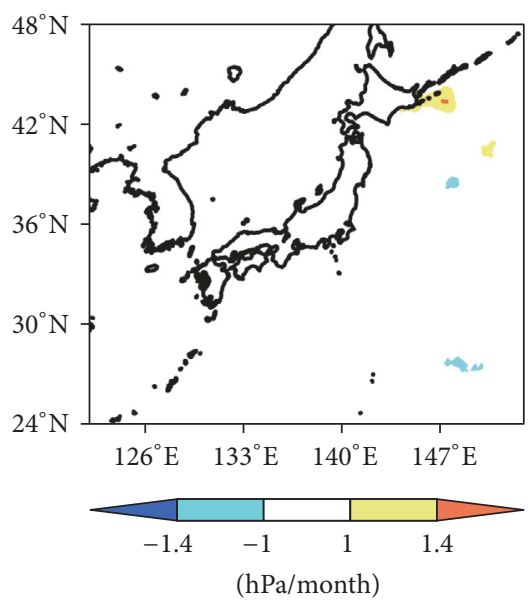

(c) LDR

FIGURE 14: (a) Difference in cyclone track frequency between the SS and CTL runs (former minus latter). (b) As in Figure 14(a) but for the $850 \mathrm{hPa}$ poleward eddy heat flux. The shading interval is $0.07 \mathrm{~K} \mathrm{~m} \mathrm{~s}^{-1}$. (c) As in Figure 14(a) but for the local deepening rate (LDR). Shading interval is $0.4 \mathrm{hPa} /$ month.

enhancement of synoptic-scale cyclone activity over the Japan Sea.

We also selected three individual cyclones that were generated and/or developed over the Japan Sea as typical cases and conducted independent CTL and MOD runs for each case. The results confirm that the Changbai Mountain Range dynamically modulates the synoptic-scale cyclones in all three cases in terms of the deformation of the cyclone's configuration, the cyclone's development, and the cyclogenesis. A vorticity budget analysis also indicates that the mountain range contributes substantially to the generation of a cyclonic vorticity anomaly within the cyclone system through the intensification of low-level wind convergence.

This study emphasizes that the Changbai Mountain Range affects the wintertime surface cyclogenesis over the Japan Sea despite the comparatively small scale of the mountains. Since cyclones that develop explosively over the Japan Sea often induce extremely strong winds, heavy snowfall, high waves, and high tides along the western coast of central and northern Japan, more precise forecasting of such cyclones is required. Our findings suggest that higher-resolution weather forecasting models with detailed topography of the Changbai Mountain may be necessary for improvements in cyclone forecasting. Another remaining issue is the role of the Japan Sea SST in the surface cyclogenesis. Although the role of the Japan Sea subpolar front was minor in this study, Yamamoto [25] demonstrated by performing SST sensitivity experiments that the Japan Sea SST has a significant impact on synoptic-scale cyclone activity. It is possible that the interannual variability of synoptic-scale cyclone activity is significantly influenced by that of the Japan Sea SST. Further studies are required.

\section{Conflicts of Interest}

The authors declare that there are no conflicts of interest regarding the publication of this paper.

\section{Acknowledgments}

This research was supported by JSPS KAKENHI Grants nos. 25242038 and $16 \mathrm{H} 01846$.

\section{References}

[1] F. Sanders and J. R. Gyakum, "Synoptic-dynamic climatology of the "Bomb" (extratropical surface cyclone)," Monthly Weather Review, vol. 108, no. 10, pp. 1589-1606, 1980.

[2] Shou-Jun Chen, Ying-Hwa Kuo, Pai-Zhong Zhang, and QiFeng Bai, "Climatology of explosive cyclones off the east Asian Coast," Monthly Weather Review, vol. 120, no. 12, pp. 3029-3035, 1992.

[3] A. Yoshida and Y. Asuma, "Structures and environment of explosively developing extratropical cyclones in the northwestern Pacific region," Monthly Weather Review, vol. 132, no. 5, pp. 1121-1142, 2004.

[4] S. Yoshiike and R. Kawamura, "Influence of wintertime largescale circulation on the explosively developing cyclones over the western North Pacific and their downstream effects," Journal of Geophysical Research Atmospheres, vol. 114, no. 13, Article ID D13110, 2009.

[5] S. Iizuka, M. Shiota, R. Kawamura, and H. Hatsushika, "Influence of the monsoon variability and sea surface temperature front on the explosive cyclone activity in the vicinity of Japan during northern winter," Scientific Online Letters on the Atmosphere, vol. 9, no. 1, pp. 1-4, 2013.

[6] T. Asai, "Meso-scale features of heavy snow falls in Japan Sea coastal regions of Japan," Tenki, vol. 35, pp. 156-161, 1988.

[7] M. Nagata, M. Ikawa, S. Yoshizumi, and T. Yoshida, "On the formation of a convergent cloud band over the Japan Sea in winter: numerical experiments," Journal of the Meteorological Society of Japan, vol. 64, pp. 841-855, 1986.

[8] M. Nagata, "On the structure of a convergent cloud band over the Japan Sea in winter: a prediction experiment," Journal of the Meteorological Society of Japan, vol. 65, pp. 871-883, 1987. 
[9] M. Nagata, "Further numerical study on the formation of the convergent cloud band over the Japan Sea in winter," Journal of the Meteorological Society of Japan, vol. 69, pp. 419-428, 1991.

[10] M. Nagata, "Meso- $\beta$-scale vortices developing along the JapanSea Polar-Airmass Convergence Zone (JPCZ) cloud band: numerical simulation," Journal of the Meteorological Society of Japan, vol. 71, no. 1, pp. 43-57, 1993.

[11] K. Tsuboki and T. Asai, "The multi-scale structure and development mechanism of mesoscale cyclones over the Sea of Japan in winter," Journal of the Meteorological Society of Japan, vol. 82, no. 2, pp. 597-621, 2004.

[12] S. Adachi and F. Kimura, "A 36-year climatology of surface cyclogenesis in East Asia using high-resolution reanalysis data," Scientific Online Letters on the Atmosphere, vol. 3, pp. 113-116, 2007.

[13] W. C. Skamarock, J. B. Klemp, J. Dudhia et al., "A description of the advanced research WRF version 3," NCAR Technical Note NCAR/TN-475+STR, National Center for Atmospheric Research, Boulder, Colo, USA, 2008.

[14] E. J. Mlawer, S. J. Taubman, P. D. Brown, M. J. Iacono, and S. A. Clough, "Radiative transfer for inhomogeneous atmospheres: RRTM, a validated correlated-k model for the longwave," Journal of Geophysical Research D: Atmospheres, vol. 102, no. 14, pp. 16663-16682, 1997.

[15] J. Dudhia, "Numerical study of convection observed during the winter monsoon experiment using a mesoscale twodimensional model," Journal of the Atmospheric Sciences, vol. 46, no. 20, pp. 3077-3107, 1989.

[16] F. Chen, R. A. Pielke, and K. Mitchell, "Development and application of land-surface models for mesoscale atmospheric models: problems and promises," in Land Surface Hydrology, Meteorology, and Climate: Observations and Modeling, V. Lakshmi, J. Albertson, and J. Schaake, Eds., vol. 3 of Water Science and Application, pp. 107-135, American Geophysical Union, Washington, DC, USA, 2001.

[17] J. S. Kain, "The Kain-Fritsch convective parameterization: an update," Journal of Applied Meteorology, vol. 43, no. 1, pp. 170$181,2004$.

[18] S.-Y. Hong and J.-O. J. Lim, "The WRF single-moment 6class microphysics scheme (WSM6)," Journal of the Korean Meteorological Society, vol. 42, pp. 129-151, 2006.

[19] R. W. Reynolds, T. M. Smith, C. Liu, D. B. Chelton, K. S. Casey, and M. G. Schlax, "Daily high-resolution-blended analyses for sea surface temperature," Journal of Climate, vol. 20, no. 22, pp. 5473-5496, 2007.

[20] M. Hayasaki and R. Kawamura, "Cyclone activities in heavy rainfall episodes in Japan during spring season," Scientific Online Letters on the Atmosphere, vol. 8, no. 1, pp. 45-48, 2012.

[21] R. S. Lindzen and B. Farrell, "A simple approximate result for the maximum growth rate of baroclinic instabilities," Journal of the Atmospheric Sciences, vol. 37, no. 7, pp. 1648-1654, 1980.

[22] A. Kuwano-Yoshida, "Using the local deepening rate to indicate extratropical cyclone activity," Scientific Online Letters on the Atmosphere, vol. 10, no. 1, pp. 199-203, 2014.

[23] S. Kobayashi, Y. Ota, Y. Harada et al., "The JRA-55 reanalysis: general specifications and basic characteristics," Journal of the Meteorological Society of Japan, vol. 93, no. 1, pp. 5-48, 2015.

[24] M. A. Shapiro and D. Keyser, "Fronts, jet streams, and the tropopause," in Extratropical Cyclones: The Erik Palmén Memorial Volume, C. W. Newton and E. O. Holopainen, Eds., pp. 167191, American Meteorological Society, 1990.
[25] M. Yamamoto, "Effects of a semienclosed ocean on extratropical cyclogenesis: the dynamical processes around the Japan Sea on 23-25 January 2008," Journal of Geophysical Research Atmospheres, vol. 118, no. 18, pp. 10391-10404, 2013. 

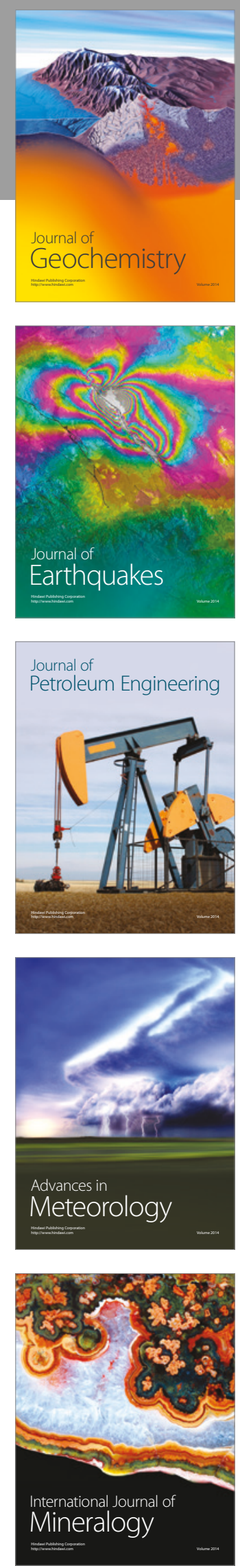
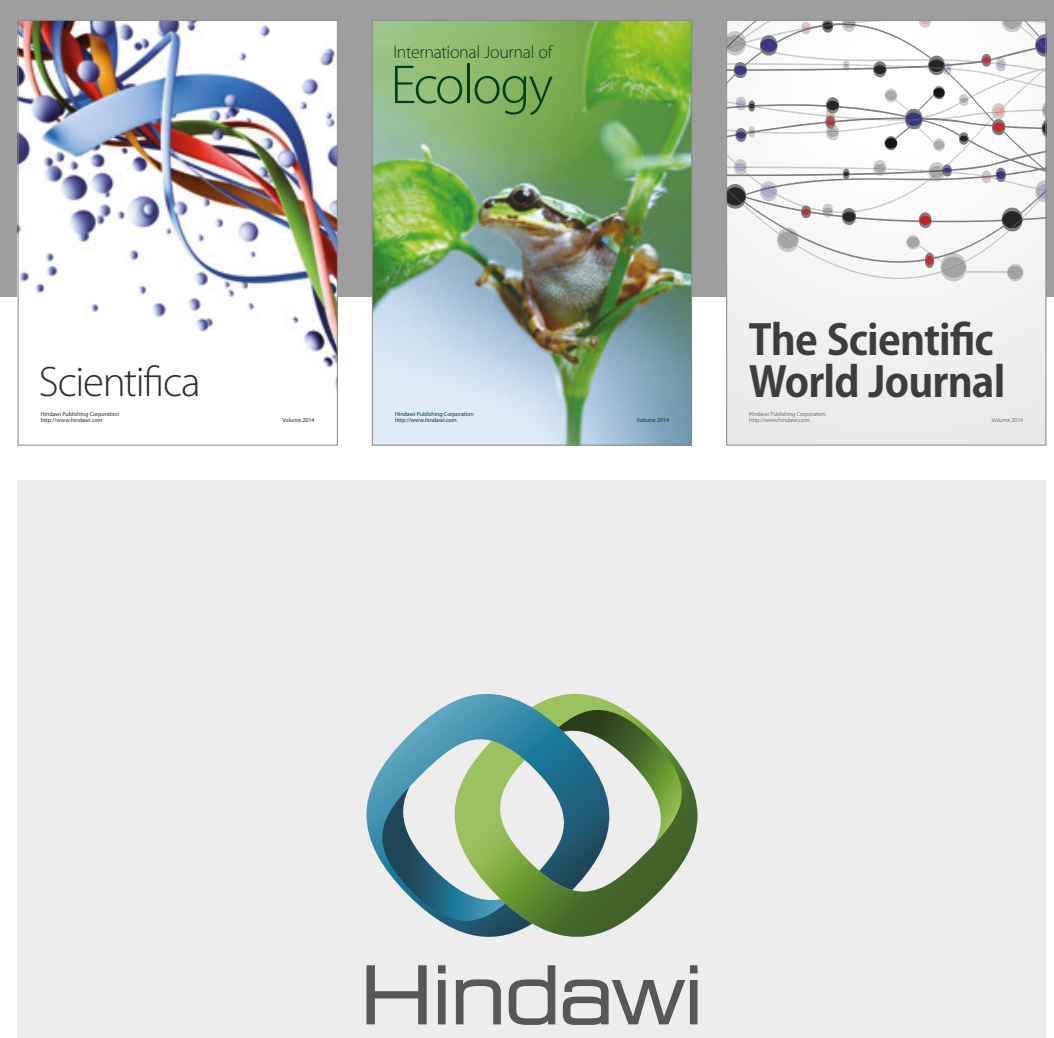

Submit your manuscripts at

https://www.hindawi.com
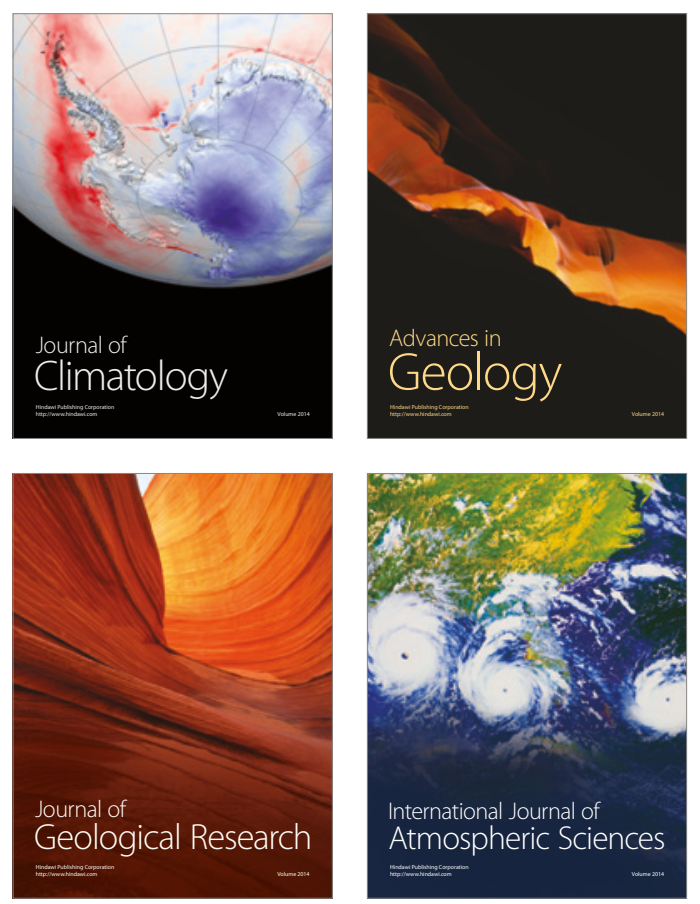

The Scientific

World Journal
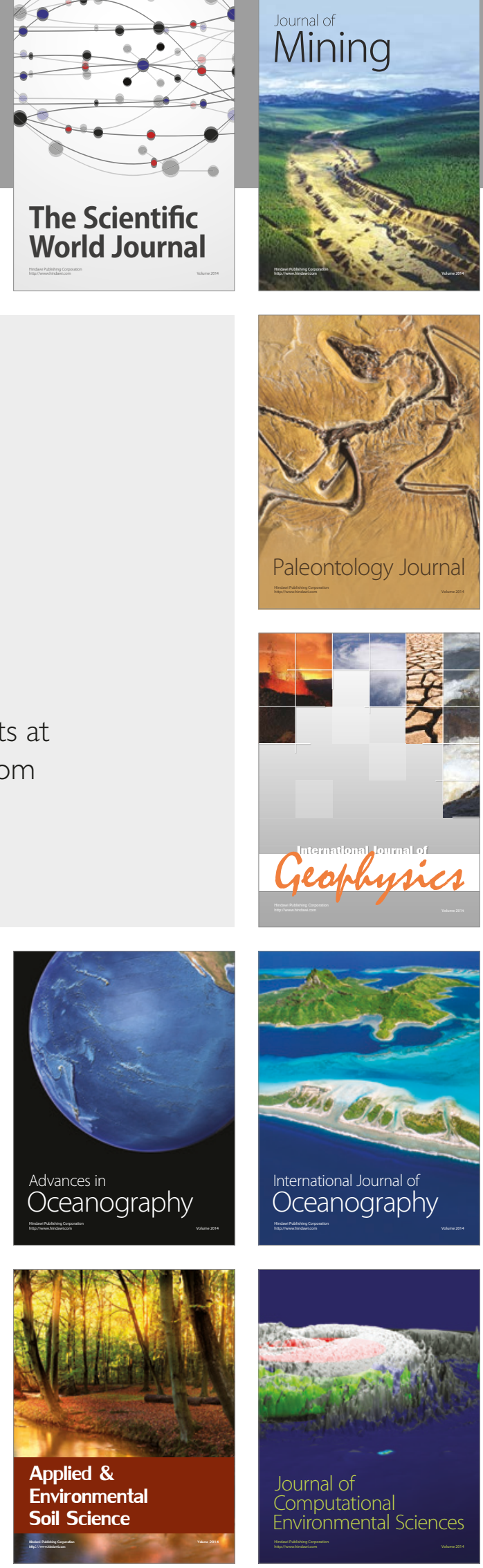